\title{
Polymer
}

\section{Luminescent solar concentrators based on PMMA films obtained from a red-emitting ATRP initiator}

\begin{tabular}{|r|l|}
\hline Journal: & Polymer Chemistry \\
\hline Manuscript ID & Draft \\
\hline Article Type: & Paper \\
\hline Date Submitted by the Author: & n/a \\
\hline Complete List of Authors: & $\begin{array}{l}\text { Pucci, Andrea; University of Pisa, Department of Chemistry and Industrial } \\
\text { Chemistry; Andrea Pucci, Andrea Pucci } \\
\text { Bellina, Fabio; University of Pisa, Department of Chemistry and Industrial } \\
\text { Chemistry } \\
\text { Lessi, Marco; Pisa University, Chemistry and industrial chemisty; Università } \\
\text { di Pisa } \\
\text { Iasilli, Giuseppe; Universita degli Studi di Pisa Dipartimento di Chimica e } \\
\text { Chimica Industriale, Chimica e Chimica Industriale } \\
\text { Pavone, Michele; University of Naples Federico II, Dept. Chemical Sciences } \\
\text { Munoz-Garcia, Ana; University of Naples Federico II, } \\
\text { Mori, Riccardo; University of Pisa, Department of Chemistry and Industrial } \\
\text { Chemistry }\end{array}$ \\
\hline \hline
\end{tabular}




\section{Journal Name}

\section{ARTICLE}

\section{Luminescent solar concentrators based on PMMA films obtained from a red-emitting ATRP initiator}

Received 00th January 20xx Accepted 00th January 20xx

DOI: $10.1039 / \times 0 \times x 00000 x$

www.rsc.org/

\author{
Riccardo Mori, ${ }^{a}$ Giuseppe lasilli, ${ }^{a}$ Marco Lessi, ${ }^{a}$ Ana Belén Muñoz-García, ${ }^{b}$ Michele Pavone, ${ }^{b}$ Fabio \\ Bellina, ${ }^{\mathrm{a}}$ and Andrea Pucci*a
}

This study examines for the first time the use of an aggregation-induced emission luminogen (AIEgen, TPE_RED) as the initiator to prepare red-emitting poly(methyl methacrylate) (PMMA) polymers, i.e. PMMA_TPE_RED, for the realization of high performance luminescent solar concentrators (LSCS). TPE_RED is a red-emitting AIEgen with D-A features and a 2bromo-2-methylpropanoate unit able to initiate the ATRP polymerization of MMA. PMMA_TPE_RED polymers containing the 0.98-3.05 wt.\% of TPE_RED absorb visible light in the range between 400-600 nm, and emits fluorescence around 610$650 \mathrm{~nm}$ when aggregated in solution or in the solid state, with a maximum quantum yield (QY) of 26.5\%. PMMA_TPE_RED films experience partial fluorescence quenching with TPE_RED content possibly due to auto-absorption phenomena and the formation of less emissive micro-sized clusters of chromophoric entities. Physical blend of PMMA_TPE_RED with commercially available PMMA provides film with a smooth texture and LSCs with optical efficiencies ever registered of $10 \%$ thanks to the superior light harvesting features of the homogeneously distributed AIEgen.

\section{Introduction}

Today, the driving force in solar photovoltaic (PV) technologies is lowering the cost per unit of power generated. PV module costs between 0.8-2 Euro/Wp, i.e. bringing the electricity price in some EU countries near 0.2 Euro/kWh, but still far off from that of $\sim 0.04$ Euro/kWh from fossil-fuel based power plants. ${ }^{1}$ Sunlight concentration is a promising path to cost-effective PV technologies. Compared to standard concentrators based on geometrical optics, luminescent solar concentrators (LSCs) show several advantages: low weight, high theoretical concentration factors, ability to work well with diffuse light and eventually no needs for sun tracking or cooling apparatuses. LSCs are slabs of transparent material doped with a fluorophore. ${ }^{2}$ The refractive index of the host higher than air allows to trap a fraction of the emitted photons by means of total internal reflection. Photons are then collected at the edges of the LSC to produce electric power by PV cells. Although the topic has started in the ' 80 s, LSC-PV systems have only recently received great impulse thanks to the development of new materials and modern building architectures that have inspired PV application of colourful windows. ${ }^{3,4}$ The building-integrated PV market is actually set to steadily increase promoted by the EU Energy Performance of Buildings Directive 2010/31/EU,

${ }^{a}$ Dipartmento di Chimica e Chimica Industriale, Università di Pisa, Via Moruzzi 13, 56124 Pisa, Italy. Email: andrea.pucci@unipi.it

${ }^{b}$ Dipartimento di Scienze Chimiche, Università di Napoli Federico II, Complesso Universitario Monte Sant'Angelo Via Cintia 21, 80126 Napoli, Italy

Electronic Supplementary Information (ESI) available: [details of any supplementary information available should be included here]. See DOI: 10.1039/x0xx00000x which states that each new building should be made 'nearly zero energy' from 2020 onwards. $^{5}$ The use of plastics and consolidated industrial processes offer encouraging means to include solar energy to the built environment. Nevertheless, LSCs are plagued by critical processes that hinder their ability to deliver light to PV cells, including fluorescence quenching due to dye aggregation. ${ }^{2,6}$ Sloff $^{7}$ described a stacked device based on poly (methyl methacrylate) (PMMA) embedding perylene-based fluorophores with power conversion efficiencies (PCE) of $7.1 \%$, which is the highest value ever reported for LSC-PV. Several strategies have been already proposed aimed at maximising LSCs performances, ${ }^{8,9}$ essentially based on the use of redemitting fluorophores characterized by large Stokes shift and negligible aggregation induced quenching. ${ }^{9-15}$ In the continuous search for novel alternatives to perylene-based fluorophores, we have recently proposed the use of red-emitting aggregation induced emission fluorophores (hereafter AIE) as excellent alternative dopants for LSCs. Indeed, AIE are non-emissive when dissolved in good solvents, but became highly luminescent in poor solvents or in solid state. ${ }^{16,17}$ Such feature enables AIE to find high-tech applications as chemo-(bio)sensors, and solidstate emitters and in LSC as well. ${ }^{18-24}$ The investigated redemitting AIE (TPE-AC) with a QY of $50 \%$ and dispersed in PMMA at moderate concentration (0.1-1.5 wt.\%) yielded worthy optical efficiencies of $6.7 \% .{ }^{25}$ Nevertheless, compatibility issues adversely affected the light harvesting features of the LSC thus keeping the device performances below but very close those of the state of the art.

In this contribution, a novel AIE fluorophore (TPE_RED, Figure 1) was synthesized and utilized as the initiator to prepare red- 
emitting poly(methyl methacrylate) polymers (PMMA_TPE_RED) via atom transfer radical polymerization (ATRP). ${ }^{26}$ Notably, ATRP was selected to control the introduction of the fluorophore on the macromolecular backbone to assure the device phase stability required for maximizing LSC performances.

\section{$<$ Figure 1 near here>}

The light concentration and optical efficiencies of the derived thin films were determined as a function of film composition and thickness and compared with PMMA blend films previously investigated.

\section{Experimental}

\section{Materials}

Unless otherwise stated, all reactions were performed under argon by standard syringe, cannula and septa techniques. $\mathrm{CuBr}$ (Sigma-Aldrich) was purified by washing with glacial acetic acid followed by diethyl ether, dried under vacuum and stored under nitrogen. Anisole (Sigma-Aldrich) was refluxed over sodium for three hours, distilled and stored under nitrogen. DCM was refluxed over $\mathrm{CaH}_{2}$ for one hour, distilled and stored under Argon. THF was refluxed over $\mathrm{LiAlH}_{4}$ for 3 hours, distilled and stored under Ar. Zinc dust (Sigma-Aldrich, < 10 micron), DMF anhydrous (Sigma-Aldrich) and ethane1,2-diol anhydrous (Sigma-Aldrich) were used as received. Sigma-Aldrich precoated silica gel PET foils were used for TLC analyses. Poly(methyl methacrylate) (PMMA, Sigma-Aldrich, $\mathrm{Mw}=350,000 \mathrm{~g} / \mathrm{mol}$, acid number $<1 \mathrm{mg} \mathrm{KOH} / \mathrm{g}$ ) was used as received.

\section{Synthesis of TPE_RED}

Preparation of 4,4'-(2-(4-bromophenyl)-2-phenylethene-1,1diyl)bis( $N, N$-dimethylaniline) (4).

According to a literature procedure, ${ }^{27}$ bis(4(dimethylamino)phenyl)methanone (2) (1.34 g, $5 \mathrm{mmol}, 1$ equiv), (4-bromophenyl)(phenyl)methanone (3) (1.70 g, 6.5 mmol, 1.3 equiv) and $\mathrm{Zn}$ (dust) ( $1.85 \mathrm{~g}, 28.3 \mathrm{mmol}, 5.6$ equiv) and THF dry were suspended in anhydrous THF. The resulting mixture was cooled to $-78{ }^{\circ} \mathrm{C}$, and $\mathrm{TiCl}_{4}(1.8 \mathrm{~mL}, 3.11 \mathrm{~g}, 16.4$ mmoli, 3.3 equiv) was added dropwise. The mixture was then slowly warmed to room temperature, and subsequently stirred for 8 hours at reflux. After cooling to room temperature DCM $(200 \mathrm{~mL})$ was added and the resulting suspension was filtered over a pad of Celite ${ }^{\circledast}$. The solution was washed with $10 \% \mathrm{wt}$ $\mathrm{NaHCO}_{3}$, and the aqueous phase back-extracted with DCM (3 $\mathrm{x}$ $30 \mathrm{~mL}$ ). The organic phase was dried over anhydrous $\mathrm{Na}_{2} \mathrm{SO}_{4}$, filtered and concentrated at reduced pressure. The residue was purified by flash chromatography on silica gel using a mixture of petroleum ether and ethyl acetate $(85: 15)$ as eluent. The chromatographic fractions containing the required product were collected and concentrated at reduced pressure to give 4 as a yellow solid $(0.85 \mathrm{~g}, 34 \%$ yield). GLC analysis showed that 4 had chemical purity higher than $98 \%$. Its spectral properties were in agreement with those previously reported. ${ }^{27}$ $\delta \mathrm{H}\left(400 \mathrm{MHz} ; \mathrm{CDCl}_{3} ; \mathrm{TMS}\right)$ 7.21-7.19 (m, 2H), 7.12-7.01 (m, 6H), 6.91-6.86 (m, 5H), 6.48-6.42 (m, 4H), $2.91(\mathrm{~s}, 6 \mathrm{H}), 2.88(\mathrm{~s}, 6 \mathrm{H})$. EI-MS: $\mathrm{m} / \mathrm{z}$ 499.1(30\%), 498.1( $\left.\mathrm{M}^{+}, 100\right), 497.1(36), 496.1(96)$.

Preparation of 4-(2,2-bis(4-(dimethylamino)phenyl)-1phenylvinyl)benzaldehyde (5).

According to a literature procedure, ${ }^{27} 4,4$ '-(2-(4-bromophenyl)2-phenylethene-1,1-diyl)bis( $N, N$-dimethylaniline) (4) $(550 \mathrm{mg}$, $1.2 \mathrm{mmol}, 1$ equiv) and anhydrous THF $(22 \mathrm{~mL})$ were added to the reaction vessel. The resulting mixture was cooled to $-78{ }^{\circ} \mathrm{C}$, and a solution of $n$-BuLi in hexane $(900 \mu \mathrm{L}, 1.2 \mathrm{mmol}, 1.33 \mathrm{M}, 1$ equiv) was added. After further $2 \mathrm{~h}$ under stirring at $-78^{\circ} \mathrm{C}, 0.95$ $\mathrm{mL}$ of anhydrous DMF (877 mg, $12.0 \mathrm{mmol}, 10$ equiv) were added, and the reaction mixture was subsequently slowly warmed to room temperature, stirred for further two hours, and poured into a saturated aqueous $\mathrm{NaCl}$ solution $(20 \mathrm{~mL})$. The aqueous layer was extracted with DCM $(3 \times 20 \mathrm{~mL})$, and the combined organic extracts were dried over anhydrous $\mathrm{Na}_{2} \mathrm{SO}_{4}$, filtered and concentrated at reduced pressure. The residue was purified by flash chromatography on silica gel using a mixture of petroleum ether and ethyl acetate $(85: 15)$ as eluent. The chromatographic fractions containing the required product were collected and concentrated at reduced pressure to give $\mathbf{5}$ as an orange solid (236 mg, 48\%). GLC analysis showed that $\mathbf{5}$ had chemical purity higher than $98 \%$. Its spectral properties were in agreement with those previously reported. ${ }^{27}$

$\delta \mathrm{H}\left(400 \mathrm{MHz} ; \mathrm{CDCl}_{3} ; \mathrm{TMS}\right) 9.88(\mathrm{~s}, 1 \mathrm{H}), 760-758(\mathrm{~m}, 2 \mathrm{H}), 7.19-$ $7.02(\mathrm{~m}, 7 \mathrm{H}), 6.90-6.87(\mathrm{~m}, 4 \mathrm{H}), 6.45-6.43(\mathrm{~m}, 4), 2.90-2.88(\mathrm{~m}$, $12 \mathrm{H})$.

EI-MS: m/z 448.3 (7\%), 447.4 (35), $446.3\left(\mathrm{M}^{+}, 100\right), 253.2$ (4), $252.2(4)$.

Preparation of 2-hydroxyethyl 2-bromo-2-methylpropanoate.

According to a literature procedure, ${ }^{28}$ 2-bromo-2methylpropanoyl bromide $(1.25 \mathrm{~mL}, 2.32 \mathrm{~g}, 10 \mathrm{mmol})$ was dropwise added at $0{ }^{\circ} \mathrm{C}$ to anhydrous ethane1,2-diol $(14 \mathrm{~mL}$, $15.6 \mathrm{~g}, 250 \mathrm{mmol}, 24.8$ equiv). The resulting solution was stirred for 3 hours at $0{ }^{\circ} \mathrm{C}$, then water $(10 \mathrm{~mL})$ was added and the solution was treated with $\mathrm{CHCl}_{3}(3 \times 10 \mathrm{~mL})$. The combined organic extracts were washed with aq $\mathrm{NaCl}_{\text {(sat) }}(3 \times 5 \mathrm{~mL})$, dried over anhydrous $\mathrm{Na}_{2} \mathrm{SO}_{4}$, filtered and concentrated at reduce pressure. The residue was fractionally distilled to give the required compound $(1.70 \mathrm{~g}, 81 \%)$ as a colorless liquid (b.p.: 85 ${ }^{\circ} \mathrm{C} / 30 \mathrm{mmHg}$ ). The spectral properties of this compound are in agreement with those previously reported. ${ }^{28}$

$\delta \mathrm{H}\left(400 \mathrm{MHz} ; \mathrm{CDCl}_{3} ; \mathrm{TMS}\right) 4.30(\mathrm{~m}, 2 \mathrm{H}), 3.87(\mathrm{~m}, 2 \mathrm{H}), 2.83$ (bs, 1H) $1.96(\mathrm{~s}, 6 \mathrm{H})$.

$\delta \mathrm{C}\left(100 \mathrm{MHz} ; \mathrm{CDCl}_{3}\right) 171.8,67.4,60.6,55.9,30.4(2 \mathrm{C})$.

Preparation of 2-(2-cyanoacetoxy)ethyl 2-bromo-2methylpropanoate (6) 
To a solution of 2-cyanoacetic acid $(0.85 \mathrm{~g}, 10 \mathrm{mmol}, 1.24$ equiv), DCC ( $2.1 \mathrm{~g}, 10.2 \mathrm{mmol}, 1.3$ equiv) and DMAP $(0.12 \mathrm{~g}, 1$ mmol, 12.5 mol\%) in anhydrous DCM (40 mL) was added a solution of 2-hydroxyethyl 2-bromo-2-methylpropanoate (1.70 $\mathrm{g}, 8.0 \mathrm{mmol})$ in anhydrous DCM $(2 \mathrm{~mL})$. The resulting mixture was stirred for 48 hours at room temperature, diluted with DCM $(30 \mathrm{~mL})$, and the resulting suspension was filtered over a pad of Celite ${ }^{\oplus}$. The organic phase was washed with aqueous $\mathrm{NaOH}(3 \mathrm{x}$ $10 \mathrm{~mL}, 10 \% \mathrm{wt}$ ) and the aqueous phase was extracted with DCM $(3 \times 10 \mathrm{~mL})$. The combined organic extracts were dried over anhydrous $\mathrm{Na}_{2} \mathrm{SO}_{4}$, filtered and concentrated at reduce pressure. The residue was purified by flash chromatography on silica gel with a mixture of petroleum ether and ethyl acetate (60:40) as eluent. The chromatography fractions contained the required product were collected and concentrated at reduce pressure to give 6 as a colorless liquid $(860 \mathrm{mg}, 39 \%$ ).

$\delta \mathrm{H}\left(400 \mathrm{MHz} ; \mathrm{CDCl}_{3} ; \mathrm{TMS}\right)$ 4.50-4,47 (m, 2H), 4.45-4.42 (m, 2H), $3.54(\mathrm{~s}, 2 \mathrm{H}), 1.94(\mathrm{~s}, 6 \mathrm{H})$.

$\delta \mathrm{C}\left(100 \mathrm{MHz} ; \mathrm{CDCl}_{3}\right) 171.4,163.2,113.2,64.0,63.0,55.6,30.6$ (2C), 24.7.

Preparation of TPE_RED (1)

To a stirred solution of 4-(2,2-bis(4-(dimethylamino)phenyl)-1phenylvinyl)benzaldehyde (5) (135 $\mathrm{mg}, 0.3 \mathrm{mmol}$ ) in anhydrous DCM $(20 \mathrm{~mL})$ were sequentially added a solution of 2-(2cyanoacetoxy)ethyl 2-bromo-2-methylpropanoate (6) (166 mg, $0.6 \mathrm{mmol}, 2$ equiv) in anhydrous DCM $(5 \mathrm{~mL})$, and 1 drop of piperidine. The resulting mixture was stirred for 6 hours at reflux. After been cooled to room temperature, the reaction mixture was poured into water $(15 \mathrm{~mL})$ and extracted with DCM $(2 \times 20 \mathrm{~mL})$. The organic extract was dried over anhydrous $\mathrm{Na}_{2} \mathrm{SO}_{4}$, filtered and concentrated at reduce pressure. The residue was purified by flash chromatography on silica gel with a mixture of petroleum ether and ethyl acetate (70:30) as eluent. The chromatographic fractions containing the required product were collected and concentrated at reduce pressure to give 1 as a red solid (180 mg, 85\%).

$\delta \mathrm{H}\left(400 \mathrm{MHz} ; \mathrm{CDCl}_{3}\right.$; TMS) $8.05(\mathrm{~s}, 1 \mathrm{H}), 7.67-7.65(\mathrm{~m}, 2 \mathrm{H}), 7.08-$ $6.95(\mathrm{~m}, 7 \mathrm{H}), 6.83-6.81(\mathrm{~m}, 5 \mathrm{H}), 6.40-6.35(\mathrm{~m}, 4 \mathrm{H}), 4-48-4.47(\mathrm{~m}$, $2 \mathrm{H}), 4.42-4.41(\mathrm{~m}, 2 \mathrm{H}), 2.85-2.83(\mathrm{~m}, 12 \mathrm{H}), 1.88(\mathrm{~s}, 6 \mathrm{H})$.

$\delta \mathrm{C}\left(100 \mathrm{MHz} \mathrm{CDCl}_{3}\right) 171.5,162.8,155.3,152.7,152.3,149.3$, $149.1,144.5,132.8(6 \mathrm{C}), 132.4(4 \mathrm{C}), 131.6(2 \mathrm{C}), 130.9(4 \mathrm{C})$, 127.9 (4C), 126.1, 116.0, $111.4(2 \mathrm{C}), 111.2(2 \mathrm{C}), 99.7,63.4,63.2$, $55.5,30.7(2 \mathrm{C})$.

HRMS (ESI) $\mathrm{m} / \mathrm{z}$ found 706.2275; $\mathrm{C}_{40} \mathrm{H}_{40} \mathrm{O}_{4} \mathrm{~N}_{2} \mathrm{Br}$ requires 706.2264

\section{Synthesis of PMMA_TPE_RED polymers}

As one example, $\mathrm{CuBr}(10 \mathrm{mg}, 0.07 \mathrm{mmol})$, TPMA (20 mg, 0.07 mmol), PMDETA (0.106 g, $0.61 \mathrm{mmol}), \mathrm{MMA}(2 \mathrm{~g}, 19.9 \mathrm{mmol})$ and $4 \mathrm{~mL}$ of anhydrous anisole were introduced in a schlenk tube and degassed with three freeze-pump-thaw cycles. Then
TPE_RED (10 mg, $0.014 \mathrm{mmol}$ ) was added and after three freeze-pump-thaw cycles the polymerization was left to proceed for $24 \mathrm{~h}$ at $90{ }^{\circ} \mathrm{C}$ under nitrogen atmosphere. The polymer was purified by repeated precipitations from chloroform into hexane and then dried at reduced pressure. $0.980 \mathrm{~g}$ of a red solid were recovered (yield $49 \%$ ).

\section{Preparation of PMMA_TPE_RED films}

Optically clear glass slides were prepared by cleaning in $6 \mathrm{M} \mathrm{HCl}$ for $12 \mathrm{~h}$, rinsing with water, acetone and 2-propanol and then drying for $8 \mathrm{~h}$ at $120^{\circ} \mathrm{C}$. As one example, PMMA_TPE_RED film with a thickness of $25 \pm 5 \mu \mathrm{m}$ (Starrett micrometer) was prepared by pouring about $0.8 \mathrm{~mL}$ chloroform $\left(\mathrm{CHCl}_{3}\right)$ solution containing about $60 \mathrm{mg}$ of the polymer on $35 \times 50 \mathrm{~mm}$ glass surface. Solvent evaporation was carried out on a warm plate $\left(30^{\circ} \mathrm{C}\right)$ and in a closed environment. The polymer films were easily removed with a spatula after immersion in water so that they can be stored for successive measurements by attaching them on $50 \times 50 \times 3 \mathrm{~mm}$ optically pure glass substrate (Edmund Optics Ltd BOROFLOAT window 50x50 TS) with a high-purity silicone oil (poly(methylphenyl siloxane), 710 fluid, Aldrich, refractive index $\mathrm{n}=1.5365$ ). Absorption and emission properties of such devices showed negligible differences with the freshly prepared ones. The films thickness was adjusted by increasing the amount of the polymer dissolved in solution. In case of PMMA_TPE_RED/PMMA blend films, appropriate amounts of $P M M A$ were dissolved in the $\mathrm{CHCl}_{3}$ solution in the presence of PMMA_TPE_RED.

\section{Computational analysis}

We performed quantum chemical calculations with the G09 suite of programs ${ }^{29}$ within the framework of density functional theory (DFT). The electronic ground state minimum-energy conformations have been optimized at the B3LYP/TZVP level of theory ${ }^{30}$ including an empirical dispersion correction (D3BJ). ${ }^{31}$ All the excited state properties (i.e. vertical excitation energies, S1 minimum-energy structure and electronic emission) have been characterized with time-dependent DFT (TD-DFT) exploiting the same triple- $\zeta$ polarized basis set and the CAMB3LYP density functional. ${ }^{32}$ This level of theory has been proven to be very effective for long-range intra-molecular chargetransfer excitation and excited state properties. ${ }^{33}$ In order to take into account the chemical environment we employed the polarizable continuum model (PCM) of implicit solvation with the dielectric constant set to that of 1,4-dioxane: for vertical excitation energies in TD-DFT we exploited a non-equilibrium formulation of the PCM self-consistent reaction field, while for emission energies we used the state-specific approach. ${ }^{34}$

\section{Characterization}

GLC analyses were performed on a Dani GC 1000 instrument equipped with a PTV injector using two types of capillary columns: an Alltech AT-35 bonded FSOT column ( $30 \mathrm{~m} \times 0.25$ $\mathrm{mm}$ i.d.) and an Alltech AT-1 bonded FSOT column (30 $\mathrm{m} \times 0.25$ $\mathrm{mm}$ i.d.). Purifications by flash chromatography were performed using silica gel Merck 60 (particle size 0.040-0.063 $\mathrm{mm}$ ). EI-MS spectra were recorded at $70 \mathrm{eV}$ by GLC-MS, 
performed on an Agilent 6890N gas-chromatograph interfaced with Agilent 5973N mass detector. NMR spectra were recorded at room temperature at $400 \mathrm{MHz}\left({ }^{1} \mathrm{H}\right)$ and $100 \mathrm{MHz}\left({ }^{13} \mathrm{C}\right)$, or 200 $\mathrm{MHz}\left({ }^{1} \mathrm{H}\right)$ and $50.3 \mathrm{MHz}\left({ }^{13} \mathrm{C}\right)$ and were referred to TMS or to the residual protons of deuterated solvents. ESI-Q/ToF flow injection analyses (FIA) were carried out using a 1200 Infinity HPLC (Agilent Technologies, USA), coupled to a Jet Stream ESI interface (Agilent) with a Quadrupole-Time of Flight tandem mass spectrometer 6530 Infinity Q-TOF (Agilent Technologies). Two sets of eluents were used: $100 \% \mathrm{MeOH}$ or $85 \% \mathrm{H}_{2} \mathrm{O}$ and $15 \%$ acetonitrile, both added with $1 \%$ formic acid. The flow rate was $0.2 \mathrm{~mL} / \mathrm{min}$. Injection volume: $3 \mathrm{~mL}$. The ESI operating conditions were: drying gas $\left(\mathrm{N}_{2}\right.$, purity $\left.>98 \%\right)$ : $350{ }^{\circ} \mathrm{C}$ and 10 $\mathrm{L} / \mathrm{min}$; capillary voltage $4.5 \mathrm{KV}$; nebuliser gas $35 \mathrm{psig}$; sheath gas $\left(\mathrm{N}_{2}\right.$, purity $\left.>98 \%\right): 375{ }^{\circ} \mathrm{C}$ and $11 \mathrm{~L} / \mathrm{min}$. Gel permeation chromatography (GPC) was used to determine molecular weights and molecular weight dispersion $\left(M_{w} / M_{n}\right)$ of polymer samples with respect to polystyrene standards. GPC measurements were performed in $\mathrm{CHCl}_{3}$ as solvent on a fourchannel pump PU-2089 Plus chromatograph (Jasco, Easton, MD, USA) equipped with a Jasco RI 2031 Plus refractometer and a multichannel Jasco UV-2077 Plus UV-Vis detector set at 252 and $360 \mathrm{~nm}$. The flow rate was $1 \mathrm{mLmin}^{-1}$ at a temperature of $30^{\circ} \mathrm{C}$ held through a Jasco CO 2063 Plus Column Thermostat. A series composed by two PLgel ${ }^{\mathrm{TM}}$ MIXED D columns and a PLgel $^{\mathrm{TM}}$ precolumn (Polymer Laboratories, Church Stretton, UK) packed with polystyrene-divinylbenzene was used to perform the analysis (linearity range $100 \mathrm{Da}-400 \mathrm{kDa}$ ).

The thermal behaviour was evaluated by differential scanning calorimetry (DSC) under nitrogen atmosphere by using a Mettler Toledo StarE System, equipped with a DSC822c module. Films were heated from 25 to $150^{\circ} \mathrm{C}$ at $10{ }^{\circ} \mathrm{C} / \mathrm{min}$ (1st heating), cooled to $0{ }^{\circ} \mathrm{C}$ at the same scan rate (1st cooling), then heated again to $150{ }^{\circ} \mathrm{C}$ at $10{ }^{\circ} \mathrm{C} / \mathrm{min}$ (2nd heating) after $5 \mathrm{~min}$ of annealing.

Spectrophotometric measurements were performed using a Perkin-Elmer Lambda 650 spectrometer with temperature control to within $\pm 0.1^{\circ} \mathrm{C}$. The chemical composition of polymers was evaluated by UV-Vis spectroscopy by means of a calibration curve obtained from $5 \times 10^{-7}-1 \times 10^{-5} \mathrm{CHCl}_{3}$ solutions of TPE_RED. The fluorescence measurements in solution (with temperature control to within $\pm 0.1^{\circ} \mathrm{C}$ ) and in the solid state were performed using a Horiba Jobin-Yvon Fluorolog ${ }^{\circledR}-3$ spectrofluorometer equipped with a $450 \mathrm{~W}$ xenon arc lamp and double-grating both excitation and emission monochromators. The emission quantum yields of the solid samples were obtained by means of a $152 \mathrm{~mm}$ diameter "Quanta-phi" integrating sphere, coated with Spectralon and mounted in the optical path of the spectrofluorometer, using as excitation source the $450 \mathrm{~W}$ Xenon lamp coupled with a doublegrating monochromator for selecting wavelengths. The size distribution of the TPE_RED aggregates was measured in a DMSO/water mixture (5/95 by vol) by means of a BeckmanCoulter Delsa ${ }^{\mathrm{TM}}$ Nano $\mathrm{C}$ dynamic light scattering at $25^{\circ} \mathrm{C}$. The optical microscope analysis was accomplished on a Reichert Polyvar optical microscope with crossed polarizers.

\section{Optical Efficiency measurement}

A home-built equipment ${ }^{25,35-37}$ was used to determine the otical efficiency of the LSCs. The system is composed by a wooden box with darkened walls and a white back scattering layer (ERGA TAPES Srl Microcellular MCPET reflective sheet). The sample holder with the photovoltaic (PV) module (IXYS SLMD121H08L mono solar cell $86 \times 14 \mathrm{~mm}$ : $\mathrm{Voc}=5.04 \mathrm{~V}, \mathrm{Isc}=50.0 \mathrm{~mA}, \mathrm{FF}>70 \%$, $\eta=22 \%$, Figure $\mathrm{S} 1$ ) is placed $2.5 \mathrm{~cm}$ above the scattering layer. The PV cell is masked with black tape to match the LSC edge $(50 \times 3 \mathrm{~mm})$ so that limiting the stray light to negligible levels. The other three edges of the LSC were covered with a reflective aluminium tape. A led lamp ( $12 \mathrm{~V} \mathrm{DC} 5 \mathrm{~W}$, colour T = 5500K) was housed $10 \mathrm{~cm}$ above the sample and with the main body located outside the box to prevent its heating-up. The PV module is connected to a digital potentiometer (AD5242) controlled via I2C by an Arduino Uno (https://www.arduino.cc) microcontroller using $12 \mathrm{C}$ master library. A digital multimeter (KEITHLEY 2010) is connected in series with the circuit, between the PV module and the potentiometer, to collect the current as a function of the external load (Figure S2). Conversely, the voltage is measured by connecting the multimeter in parallel to the digital potentiometer (Figure S3). Arduino Uno controls the multimeter via SCPI language over RS-232 bus using a TTL to RS232 converter chip (MAX232). Arduino Uno is connected to pc via USB port and controlled by a Python script. A $12 \mathrm{~V}$ DC voltage light source was selected so that the luminous flux is continuous and there is no need to compensate the PV module capacitance. The measurement cycle begins with a signal from PC to Arduino which sets the multimeter parameter to measure current. Then Arduino begins the measure loop: 1) set the potentiometer to a given value; 2 ) send trigger signal to the multimeter; 3 ) read the measured data; and 4) send the data back to PC. The loop is repeated 256 times for potentiometer values ranging $60 \Omega-1$ $M \Omega$. Arduino sets the multimeter to measure voltage and for each potentiometer value the system records 8 data samples which are subsequently processed by the Python script. The optical efficiency is reported as $\eta_{\text {opt }}$ and obtained from the concentration factor, which is the ratio between the maximal current of the PV cell attached the LSC edges under illumination of a light source and the maximal current of the bare cell put perpendicular to the light source. In our setup, the QE variation of the PV module is under $2 \%$ within the emission range of from $500 \mathrm{~nm}$ to $700 \mathrm{~nm}$.

\section{Results and discussion}

\section{Synthesis of TPE_RED}

The preparation of the ATRP initiator TPE_RED (1) was performed according to a synthetic pathway, summarized in Scheme 1, whose first step consisted in the assembly of the AIE core of the molecule by a McMurry reaction involving bis(dimethylamino) benzophenone $\mathbf{2}$ and bromobenzophenone $\mathbf{3}$, both commercially available, in the presence of $\mathrm{TiCl}_{4}$ and zinc powder. $^{27}$

$<$ Scheme 1 near here> 
The resulting tetraphenylene derivative $\mathbf{4}$ was then decorated with the ATRP arm by a reaction sequence involving at first the formylation with DMF of the aryllithium derivative obtained from 4 by bromine-lithium exchange at low temperature, followed by a Knoevenagel-type condensation between the aromatic aldehyde 5 so obtained and the cyanoester $\mathbf{6}$ (Scheme 1). This last compound was easily obtained from 2-bromo-2methylpropanoyl bromide, ethylene glycol, and cyanoacetic acid following reported synthetic procedures (Scheme 2 ). ${ }^{28}$

$<$ Scheme 2 near here $>$

\section{Optical properties of TPE_RED in solution}

TPE_RED shows an absorption maximum at $498 \mathrm{~nm}$ (Figure S4) with an extinction coefficient of $7.54 \cdot 10^{3} \mathrm{M}^{-1} \mathrm{~cm}^{-1}$ and a faint emission in DMSO solution. At water fractions larger than $80 \%$, TPE_RED aggregates together, thus activating the AIE process and leading to the formation of highly emissive TPE_RED nanoparticles, as confirmed by dynamic light scattering analysis, with fluorescence peaking at $695 \mathrm{~nm}$ (Figure S5 and S6, respectively). The Stokes shift of about $190 \mathrm{~nm}$ is noteworthy and promising for application of TPE_RED in LSC.

\section{Computational analysis}

The electronic properties of the dye were also characterized by means of state-of-the-art DFT calculations. To model the chemical bonding with the polymeric matrix we substituted the $-\mathrm{Br}$ with a $-\mathrm{CH}_{3}$ group (DA_TPE depicted by Figure 2) and we found that the main features of the dye frontier orbitals are not affected by this modification. Vertical excitation energies were computed with TD-DFT considering the chemical environment of the polymer via the PCM.

<Figure 2 near here>

The computed first transition energy $\lambda_{\max }$ is at $466 \mathrm{~nm}$, in good agreement with experiments, and it involves an electronic excitation form the HOMO to the LUMO (Figure 2). The nature of these molecular orbitals confirms that the transition corresponds to a charge-transfer from the TPE moiety to the cyanoester group. Upon excitation, the dye undergoes a significant structural reorganization, especially concerning the TPE group where the double bond at its centre goes from an equilibrium distance of $1.368 \AA$ in $\mathrm{S}_{0}$ to the value of $1.440 \AA$ in $S_{1}$. The predicted value for the $S_{1}>S_{0}$ emission is at $647 \mathrm{~nm}$, again in good qualitative agreement with experiments. The structural stabilization of the excited state is the responsible for the large Stoke shift of $181 \mathrm{~nm}$.

From analysis of the MOs involved in these electronic transitions we found that a key structural parameter for the observed behaviour is the rotation across the dihedral angle $\alpha$ depicted in Figure 2. A relaxed scan of the potential energy surfaces of both ground $S_{0}$ and excited $S_{1}$ states were performed by changing the value of $\alpha$ from $0^{\circ}$ to $180^{\circ}$. The energies of each intermediate do not differ much from the ground state with a maximum relative energy of $\sim 0.4 \mathrm{eV}$, and little higher values in the excited state $(\sim 0.6 \mathrm{eV})$ as depicted by Figure $\mathrm{S} 7$. The rotation around $\alpha$ is important because when its value is $90^{\circ}$ the transition becomes forbidden, and overall the Stoke shift decreases when the dihedral angle goes from $0^{\circ} / 180^{\circ}$ to $90^{\circ}$. This result implies that the dye is most effective when its mobility is limited as in aggregates or embedded in a glassy polymer matrix such as PMMA.

\section{TPE_RED polymerization and polymers main features}

The red-emitting PMMA_TPE_RED polymers were obtained by atom transfer radical polymerization (ATRP) of methylmethacrylate (MMA) using TPE_RED as initiator. The feeding ratio of TPE_RED to MMA was varied from 0.5 to 1.5 wt.\% and the polymerization was conducted under the catalyst system $\mathrm{CuBr} / \mathrm{TPMA}$ in solution of anhydrous anisole at $90^{\circ} \mathrm{C}$ for $24 \mathrm{~h}$. The resultant PMMA_TPE_RED polymers were purified by repeated precipitations from chloroform into hexane and characterized by standard methods (Table 1 ).

$<$ Table 1 near here $>$

The chemical structure of polymers was characterized by ${ }^{1} \mathrm{H}$ NMR spectroscopy (Figure S8) with the signals attributed to PMMA only. No quantitative analysis was accomplished being the aromatic signals of the TPE below the signal to noise ratio even at the highest fluorophore content (PMMA_TPE_RED 1.5 ). The TPE_RED amounts in the polymers were therefore determined by UV-Vis spectroscopy by means of a calibration curve obtained from $5 \times 10^{-7}-1 \times 10^{-5} \mathrm{M} \mathrm{CHCl}_{3}$ solutions of TPE_RED, that is supposing negligible the variation of its molar extinction coefficient after polymerization. The TPE_RED contents calculated in the final polymers were twice than that of alimentation due to the $50 \%$ of MMA conversion. The molecular weight and polydispersity index (PDI) were studied by GPC (Figure S9). As expected, the results reveal that the degree of polymerization of MMA diminished with increasing TPE_RED feeding molar ratio. Notably, the PDI well below 2 for all polymers, agrees well with that of typical ATRP systems. ${ }^{38}$ The glass transition temperature ( $\mathrm{Tg}$, Figure $\mathrm{S} 10$ for PMMA_TPE_RED 0.75 ) was determined by DSC analysis and resulted in agreement with that of PMMA polymers with different molecular weights.

As a representative example, PMMA_TPE_RED 0.75 shows an absorption maximum at $495 \mathrm{~nm}$ and a negligible emission in $\mathrm{CHCl}_{3}$ solution (Figure 3a).

\section{<Figure 3 near here>}

At hexane (non-solvent) fractions larger than $80 \%$, PMMA_TPE_RED aggregates together, thus again activating the AIE process. At $95 \%$ hexane content, the emission intensity is about 40 fold higher than that in the pure $\mathrm{CHCl}_{3}$ solution with fluorescence peaking spanning from 618 to $607 \mathrm{~nm}$ with decreasing solution dielectric constant (Figures $3 a$ and $3 b$ ). Notwithstanding the extent of blue-shift (11 $\mathrm{nm})$, PMMA_TPE_RED aggregates still maintain a Stokes shift larger than $110 \mathrm{~nm}$.

\section{Optical properties of films}

PMMA_TPE_RED films with a thickness of $25 \pm 5 \mu \mathrm{m}$ (Starrett micrometer) were prepared by pouring about $0.8 \mathrm{~mL}$ chloroform $\left(\mathrm{CHCl}_{3}\right)$ solution containing about $60 \mathrm{mg}$ of the polymer. PMMA_TPE_RED films show (Figure 4a) a molecular 
absorption maxima at $480 \mathrm{~nm}$ with a broad absorption band from 425-550 $\mathrm{nm}$ that appears worthwhile for light harvesting in the visible range.

<Figure 4 near here>

Notably, the absorbance increases linearly with fluorophore content on passing from PMMA_TPE_RED 0.5 to PMMA_TPE_RED 1.5 , thus possibly excluding the formation of $\pi$ $\pi$ staking phenomena among the TPE_RED chromophores. By contrast, PMMA_TPE_RED films show emission features that depend on fluorophore concentration (Figure 4b). PMMA_TPE_RED 0.5 , i.e. the polymer with the lowest TPE_RED content (0.98 wt.\%, Table 1$)$ shows bright emission peaked at $650 \mathrm{~nm}$ with a significant Stokes shift of $170 \mathrm{~nm}$ that is quite similar to that of DMSO/water mixtures $(190 \mathrm{~nm})$. This emission band appears optimal for LSCs since it well superimposes with the maximum external quantum efficiency of the utilized Sibased PV cell (Figure S1). Notably, fluorescence quenching occurred with TPE_RED content higher than $1 \mathrm{wt} . \%$, and levelled off to about half of the initial emission intensity for PMMA_TPE_RED $1.0 \quad(2.04 \quad w t . \%$ of TPE_RED $)$ and PMMA_TPE_RED 1.5 (3.05 wt.\% of TPE_RED) films. The quantum yield (QY) of the polymer films was also determined (Figure $4 \mathrm{~b}$, inset). As expected, QY was maximum for the lowest TPE_RED content, i.e. around $28 \%$ for PMMA_TPE_RED 0.5 , and experienced a progressive decline with fluorophore content up to about $16 \%$ for the PMMA_TPE_RED 1.5 . Fluorescence quenching is reported in literature for highly conjugated donoracceptor AIEgens and attributed to the formation of less emissive amorphous chromophoric aggregates. ${ }^{39}$ Nevertheless, auto-absorption phenomena cannot be neglected considering also the progressive red-shift of the emission band with increasing TPE_RED content. ${ }^{15,25}$

Optical microscopy was then used to determine the resulting film morphology. Notably, the optical micrograph taken on PMMA_TPE_RED 0.5 film (Figure $5 a$ ) shows a surface with a quite smooth texture and low roughness.

$<$ Figure 5 near here>

Conversely, a substantial number of micro-sized clusters of chromophoric entities emerged at the highest TPE_RED content (PMMA_TPE_RED 1.5 film, Figure 5b), thus possibly affecting the overall luminescence response of the film. ${ }^{40}$ This phenomenon can be addressed to the reduced molecular weight of PMMA_TPE_RED 1.5 (i.e. $36400 \mathrm{~g} / \mathrm{mol}$ with respect to 201300 for PMMA_TPE_RED 0.5 , Table 1), which possibly favours TPE_RED segregation in isolated islands. Aimed at identifying and resolving this issue a PMMA_TPE_RED 1.5 film was mixed with 50 wt.\% of a commercially available high molecular weight PMMA to obtain a blend film with the same thickness and a TPE_RED content of about 1 wt.\% (50 wt.\% PMMA/PMMA_TPE_RED 1.5 ). It is worth noting that the film texture appears remarkably homogeneous without the typical roughness conferred by the chromophoric clusters (Figure 5c), thus confirming the beneficial effect of the PMMA long macromolecular chains. It was worth noting that the QY calculated for the 50 wt.\% PMMA/PMMA_TPE_RED 1.5 film was $27.6 \%$, i.e. higher than $26.5 \%$ of the PMMA TPE RED 0.5 containing the same $1 \mathrm{wt} . \%$ of
TPE_RED fluorophore. Notably, this difference is reliable being the standard error of the QY below $0.5 \%$.

\section{Optical efficiencies}

The performances of PMMA_TPE_RED polymers as LSCs were assessed as films with a thickness of $25 \pm 5 \mu \mathrm{m}$ coated over an optically pure $50 \times 50 \times 3 \mathrm{~mm}$ glass.

Photocurrent measurements were accomplished with a homebuilt apparatus by using a Si-based PV cell attached on one edge of the LSC (see experimental part). The optical efficiency $\eta_{\text {opt }}$ was determined as the ratio between the concentration factor $C$ and the geometrical factor $\mathrm{G}$ of LSC (i.e., $\mathrm{G}=16.6$ ) (Equation 1):

$\eta_{o p t}=\frac{C}{G}=\frac{I_{L S C}}{I_{S C} \cdot G}$

where $\mathrm{C}$ is the ratio between the short circuit current measured in the case of the cell over the collector edge (ILSC) and short circuit current of the PV cell when perpendicular to the light source $\left(\mathrm{I}_{\mathrm{SC}}\right)$ and $\mathrm{G}$ is the ratio between the area exposed to the light source and the collecting area. The data were reported in Table 1 and compared to those collected with the same experimental setup for PMMA films containing dispersed redemitting fluorophores recently investigated. Notably, $C$ and $\eta_{\text {opt }}$ decrease as a function of TPE_RED content, possibly due to the occurrence of dissipative phenomena and in agreement with fluorescence quantum yields (Figure $4 b$, inset). Notably, the progressive formation of less emissive TPE_RED assemblies counterbalances the effect provided by the increased number of available chromophores able to harvest and concentrate light to the Si-based PV cell. Nevertheless, PMMA_TPE_RED LSCs showed a maximum optical efficiency (7.05) higher than that calculated for previously investigated PMMA blend films containing the same concentration of red-emitting fluorophores. More specifically, the substantial difference in light concentration between PMMA_TPE_RED and TPEAC/PMMA LSCs suggest that the covalent approach proposed in this work is effective in limiting the adverse dissipative phenomena caused by compatibility issues between the fluorophore and the polymer. This feature was also effective in providing optical efficiencies higher than that calculated for PMMA films containing moderate concentration (<1.5 wt.\%) of Lumogen F Red 305 (LR) that is considered the state-of-the-art for LSCs. ${ }^{9,35}$

Furthermore, the effect of polymer thickness on the concentration efficiency of LSCs was also investigated (Figure 6). $<$ Figure 6 near here>

PMMA_TPE_RED 0.5 films with $30 \mu \mathrm{m}$ of thickness and about 1 wt.\% of TPE_RED were found to display the best trade-off for maximizing fluorophore content in the LSC without adversely affecting its overall efficiency. The maximum optical efficiency of 7.91 apparently decreased to 7.14 for $35 \mu \mathrm{m}$ thick films, possibly due to more probable dissipative dye-dye interactions caused by the larger mean path length of the emitted radiation. It is worth noting that the $30 \mu \mathrm{m}$ thick PMMA/PMMA_TPE_RED 1.5 blend film with a 1 wt.\% content of 
TPE_RED showed the highest optical efficiency of $10 \%$, possibly due to the substantial reduction of fluorophore segregation provided by the PMMA blending, as evidenced by optical microscopy (Figure 5c). This value is the highest ever registered in our laboratory with the same apparatus and LSC geometrical factor, ${ }^{14,15,25,35-37}$ thus confirming that the strategy of using well compatible and homogeneously distributed red-emitting AIE fluorophores is powerful for gaining high performances LSCs.

\section{Conclusions}

We have demonstrated that TPE_RED, a red-emitting AIEgen with D-A features can initiate the ATRP polymerization of MMA to provide polymer films suitable for the preparation of LSCs. PMMA_TPE_RED films showed fluorescence peaked in the range of $610-650 \mathrm{~nm}$ with $\max$ QY of $26.5 \%$ for the film containing the lowest TPE_RED content (0.98 wt.\%). PMMA_TPE_RED films with higher fluorophore concentration were adversely affected by auto-absorption phenomena and the formation of less emissive micro-sized clusters of fluorophores. Notably, the film surface was rendered smooth and uniform after blending PMMA_TPE_RED polymers with commercially available PMMA, which in turn results in increased emission efficiency. Nevertheless, PMMA_TPE_RED LSCs showed optical efficiencies higher than that calculated for previously investigated PMMA blend films containing the same concentration of red-emitting AIE fluorophore and with the same thickness. This result confirmed the beneficial covalent approach in effectively limiting the adverse dissipative phenomena caused by compatibility issues between the fluorophore and the polymer. In agreement with this consideration, well homogeneous PMMA/PMMA_TPE_RED blend films showed the highest optical efficiency of $10 \%$, that is the highest ever registered in our laboratory. Future approaches for $\eta_{\text {opt }}$ enhancement should adopt new synthetic strategies focused at improving AIE fluorophore distribution within the macromolecular backbone aimed at increasing $Q Y$ values for high fluorophore content. Regardless of that, all findings consistently support the effective use of red-emitting AlEgens in the realization of high performance LSCs.

\section{Acknowledgements}

The research leading to these results has received funding from the Università di Pisa under PRA 2017 (project No. 2017_28) and BIHO 2017.

\section{Notes and references}

1) J. L. Sawin, Renewables Global Status Report, Paris, 2014.

2) M. G. Debije and P. P. C. Verbunt, Advanced Energy Materials, 2012, 2, 12-35.

3) M. Debije, Nature, 2015, 519, 298-299.

4) J. L. Sawin, Renewables Global Status Report, Renewable Energy Policy Network for the 21th Century, Paris, 2014.

5) BIPV Technologies and Markets 2015-2022, Dublin, Ireland, 2015.

6) A. Goetzberger and W. Greube, Appl. Phys., 1977, 14, 123-139.
7) L. H. Slooff, E. E. Bende, A. R. Burgers, T. Budel, M. Pravettoni, R. P. Kenny, E. D. Dunlop and A. Büchtemann, physica status solidi (RRL) - Rapid Research Letters, 2008, 2, 257-259.

8) A. Bozzola, V. Robbiano, K. Sparnacci, G. Aprile, L. Boarino, A. Proto, R. Fusco, M. Laus, L. C. Andreani and D. Comoretto, Advanced Optical Materials, 2016, 4, 147-155.

9) B. McKenna and R. C. Evans, Advanced Materials, 2017, 10.1002/adma.201606491.

10) R. Rondao, A. R. Frias, S. F. H. Correia, L. Fu, V. de Zea Bermudez, P. S. Andre, R. A. S. Ferreira and L. D. Carlos, ACS Appl. Mater. Interfaces, 2017, 9, 12540-12546.

11) F. Meinardi, S. Ehrenberg, L. Dhamo, F. Carulli, M. Mauri, F. Bruni, R. Simonutti, U. Kortshagen and S. Brovelli, Nature Photonics, 2017, 11, 177-185.

12) Z. Krumer, W. G. J. H. M. van Sark, R. E. I. Schropp and C. d. M. Donega, Solar Energy Materials \& Solar Cells, 2017, 167, 133-139.

13) N. J. L. K. Davis, R. W. MacQueen, S. T. E. Jones, C. Orofino-Pena, D. Cortizo-Lacalle, R. G. D. Taylor, D. Credgington, P. J. Skabara and N. C. Greenham, Journal of Materials Chemistry C: Materials for Optical and Electronic Devices, 2017, 5, 1952-1962.

14) A. Pucci, M. Pavone, P. Minei, A. B. Munoz-Garcia, E. Fanizza, P. Cimino and A. Rodriguez, RSC Advances, 2016, 6, 1747417482.

15) J. Lucarelli, M. Lessi, C. Manzini, P. Minei, F. Bellina and A. Pucci, Dyes and Pigments, 2016, 135, 154-162.

16) R. Hu, N. L. C. Leung and B. Z. Tang, Chem. Soc. Rev., 2014, 43, 4494-4562.

17) J. Mei, N. L. C. Leung, R. T. K. Kwok, J. W. Y. Lam and B. Z. Tang, Chemical Reviews (Washington, DC, United States), 2015, 115, 11718-11940.

18) J. Mei, Y. Hong, W. Y. Lam Jacky, A. Qin, Y. Tang and Z. Tang Ben, Advanced materials (Deerfield Beach, Fla.), 2014, 26, 54295479.

19) A. Qin, J. W. Y. Lam and B. Z. Tang, Progress in Polymer Science, 2012, 37, 182-209.

20) Z. Zhao, J. W. Y. Lam and B. Z. Tang, J. Mater. Chem., 2012, 22, 23726-23740.

21) X. Cheng, R. Zhang, X. Cai and B. Liu, Journal of Materials Chemistry B, 2017, 5, 3565-3571.

22) D. Ding, K. Li, B. Liu and B. Z. Tang, Accounts of Chemical Research, 2013, 46, 2441-2453.

23) J. L. Banal, J. M. White, K. P. Ghiggino and W. W. H. Wong, Scientific Reports, 2014, 4, 4635/4631-4635/4635.

24) J. L. Banal, B. Zhang, D. J. Jones, K. P. Ghiggino and W. W. H. Wong, Accounts of Chemical Research, 2017, 50, 49-57.

25) F. De Nisi, R. Francischello, A. Battisti, A. Panniello, E. Fanizza, M. Striccoli, X. Gu, N. L. C. Leung, B. Z. Tang and A. Pucci, Materials Chemistry Frontiers, 2017, 1, 1406-1412.

26) K. Matyjaszewski and J. Xia, Chemical Reviews, 2001, 101, 29212990.

27) E. Wang, E. Zhao, Y. Hong, J. W. Y. Lam and B. Z. Tang, Journal of Materials Chemistry B, 2014, 2, 2013-2019.

28) M. A. White, J. A. Johnson, J. T. Koberstein and N. J. Turro, Journal of the American Chemical Society, 2006, 128, 11356-11357.

29) M. J. Frisch, G. W. Trucks, H. B. Schlegel, G. E. Scuseria, M. A. Robb, J. R. Cheeseman, G. Scalmani, V. Barone, G. A. Petersson, H. Nakatsuji, X. Li, M. Caricato, A. V. Marenich, J. Bloino, B. G. Janesko, R. Gomperts, B. Mennucci, H. P. Hratchian, J. V. Ortiz, A. F. Izmaylov, J. L. Sonnenberg, Williams, F. Ding, F. Lipparini, F. Egidi, J. Goings, B. Peng, A. 
Petrone, T. Henderson, D. Ranasinghe, V. G. Zakrzewski, J. Gao, N. Rega, G. Zheng, W. Liang, M. Hada, M. Ehara, K. Toyota, R. Fukuda, J. Hasegawa, M. Ishida, T. Nakajima, Y. Honda, O. Kitao, H. Nakai, T. Vreven, K. Throssell, J. A. Montgomery Jr., J. E. Peralta, F. Ogliaro, M. J. Bearpark, J. J. Heyd, E. N. Brothers, K. N. Kudin, V. N. Staroverov, T. A. Keith, R. Kobayashi, J. Normand, K. Raghavachari, A. P. Rendell, J. C. Burant, S. S. Iyengar, J. Tomasi, M. Cossi, J. M. Millam, M. Klene, C. Adamo, R. Cammi, J. W. Ochterski, R. L. Martin, K. Morokuma, O. Farkas, J. B. Foresman and D. J. Fox, Journal, 2016.

30) A. D. Becke, The Journal of Chemical Physics, 1993, 98, 56485652.

31) S. Grimme, S. Ehrlich and L. Goerigk, Journal of Computational Chemistry, 2011, 32, 1456-1465.

32) T. Yanai, D. P. Tew and N. C. Handy, Chemical Physics Letters, 2004, 393, 51-57.

33) D. Jacquemin, E. A. Perpète, G. E. Scuseria, I. Ciofini and C. Adamo, Journal of Chemical Theory and Computation, 2008, 4, 123-135.

34) J. Tomasi, B. Mennucci and R. Cammi, Chemical Reviews, 2005, 105, 2999-3094.

35) M. Carlotti, G. Ruggeri, F. Bellina and A. Pucci, Journal of Luminescence, 2016, 171, 215-220.

36) M. Carlotti, E. Fanizza, A. Panniello and A. Pucci, Solar Energy, 2015, 119, 452-460.

37) F. Gianfaldoni, F. De Nisi, G. Iasilli, A. Panniello, E. Fanizza, M. Striccoli, D. Ryuse, M. Shimizu, T. Biver and A. Pucci, RSC Advances, 2017, 7, 37302-37309.

38) T. Grimaud and K. Matyjaszewski, Macromolecules, 1997, 30, 2216-2218.

39) J. Zhou, Z. Chang, Y. Jiang, B. He, M. Du, P. Lu, Y. Hong, H. S. Kwok, A. Qin, H. Qiu, Z. Zhao and B. Z. Tang, Chemical Communications, 2013, 49, 2491-2493.

40) F. Ciardelli, G. Ruggeri and A. Pucci, Chemical Society Reviews, 2013, 42, 857-870. 


\section{Journal Name}

\section{ARTICLE}

Table 1. Characteristics of the PMMA_TPE_RED polymers

\begin{tabular}{|c|c|c|c|c|c|}
\hline Entry & $\begin{array}{c}\text { TPE_RED } \\
\text { (alimentation, wt.\%) }\end{array}$ & $\begin{array}{c}\text { TPE_RED } \\
\text { (polymer, wt.\%) }^{\mathbf{a}}\end{array}$ & $\begin{array}{c}\mathbf{M n} \\
(\mathbf{g} / \mathbf{m o l})\end{array}$ & PDI & $\begin{array}{c}\text { Tg } \\
\left({ }^{\circ} \mathbf{C}\right)\end{array}$ \\
\hline PMMA_TPE_RED 0.50 & 0.50 & 0.98 & 201300 & 1.38 & 85.5 \\
\hline PMMA_TPE_RED 0.75 & 0.75 & 1.39 & 114100 & 1.69 & 75.5 \\
\hline PMMA_TPE_RED 1.0 & 1.00 & 2.04 & 71400 & 1.35 & 68.2 \\
\hline PMMA_TPE_RED 1.5 & 1.50 & 3.05 & 36400 & 1.29 & 64.3 \\
\hline
\end{tabular}

adetermined by UV-Vis spectroscopy

Table 2. Concentration factors $(C)$ and optical efficiencies $\left(\eta_{\text {opt }}\right)$ calculated for PMMA_TPE_RED films and for redemitting fluorophore/PMMA blend films. ${ }^{25,37}$ Films thickness of $25 \pm 5 \mu \mathrm{m}$.

\begin{tabular}{|c|c|c|}
\hline Entry & C & $\eta_{\text {opt }}(\%)$ \\
\hline PMMA_TPE_RED $0.5(0.98$ wt.\%) & $1.17 \pm 0.03$ & 7.05 \\
\hline PMMA_TPE_RED 0.75 (1.39 wt.\%) & $1.16 \pm 0.04$ & 6.97 \\
\hline PMMA_TPE_RED $1.0(2.04 \mathrm{wt} . \%)$ & $1.14 \pm 0.04$ & 6.85 \\
\hline PMMA_TPE_RED $1.5(3.05$ wt.\%) & $1.09 \pm 0.03$ & 6.52 \\
\hline TPE-AC/PMMA (1.0 wt.\%) $)^{25}$ & $0.86 \pm 0.03$ & 5.20 \\
\hline TPE-AC/PMMA (1.5 wt.\%) & $0.85 \pm 0.04$ & 5.10 \\
\hline LR/PMMA (1.0 wt.\%) ${ }^{37}$ & $1.12 \pm 0.04$ & 6.75 \\
\hline LR/PMMA (1.5 wt.\%) $)^{37}$ & $1.22 \pm 0.04$ & 7.26 \\
\hline
\end{tabular}




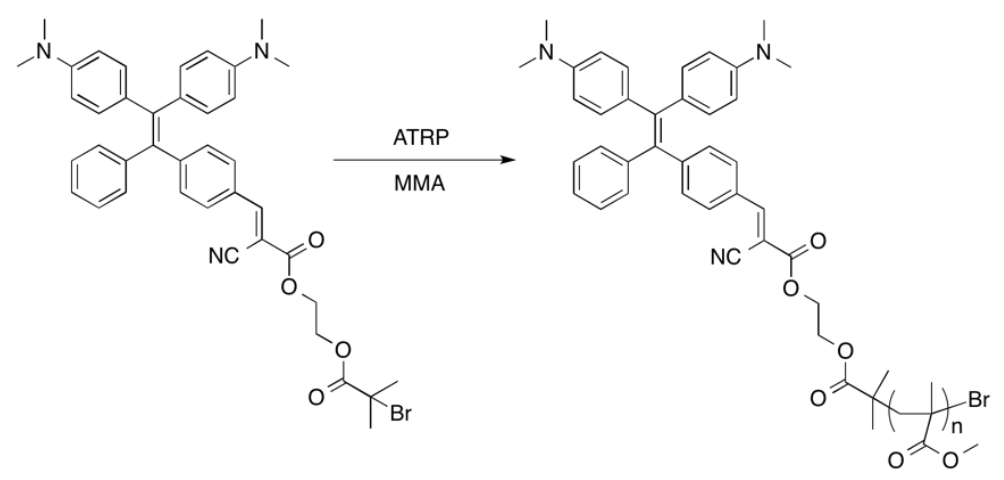

Figure 1. Chemical structure of 2-((2-bromo-2-methylpropanoyl)oxy)ethyl (E)-3-(4-(2,2'-bis(4-(dimethylamino)phenyl)-1phenylvinyl)phenyl)-2-cyanoacrylate (TPE_RED) and the derived PMMA-based polymer (PMMA_TPE_RED)<smiles>CN(C)c1ccc(C(=O)[O+]=C(c2ccccc2)c2ccc(C(=C(c3ccccc3)c3ccc(C=O)cc3)c3ccc(N(C)C)cc3)cc2)cc1</smiles>

Scheme 1 Synthetic pathway to TPE_RED (1). Reaction reagents and conditions: (i) (a) 2 (5 mmol), 3 (1.3 equiv), Zn powder (5.7 equiv), $\mathrm{THF},-78^{\circ} \mathrm{C}$; (b) $\mathrm{TiCl}_{4}$ (3.3 equiv), $-78^{\circ} \mathrm{C}$ to $\mathrm{RT}$; (c) reflux, $8 \mathrm{~h}$ (34 \%). (ii) (a) 4 (0.50 mmol, 1.1 equiv), $n$-BuLi $1.54 \mathrm{M}$ in hexane (1.0 equiv), THF, $-78^{\circ} \mathrm{C}, 2 \mathrm{~h}$; (b) DMF (11 equiv), - $78^{\circ} \mathrm{C}$ to RT, $2 \mathrm{~h}$ (48\%). (iii) 2-(2-cyanoacetoxy)ethyl 2-bromo-2-methylpropanoate (6) (2.0 equiv), pyperidine ( 3 drops), $\mathrm{CH}_{2} \mathrm{Cl}_{2}$, reflux, $24 \mathrm{~h}$ ( $85 \%$ ). 
<smiles>CC(C)(Br)C(=O)OCCOC(=O)C(C)(C)Br</smiles>

Scheme 2 Synthetic pathway to 2-(2-cyanoacetoxy)ethyl 2-bromo-2-methylpropanoate (6). Reaction reagents and conditions: (i) ethylene glycol ( 25 equiv), $0{ }^{\circ} \mathrm{C}, 3 \mathrm{~h}(81 \%)$. (ii) cyanoacetic acid (1.24 equiv), DCC (1.3 equiv), DMAP (0.12 equiv), CH2Cl2, rt, $48 \mathrm{~h}$ $(39 \%)$

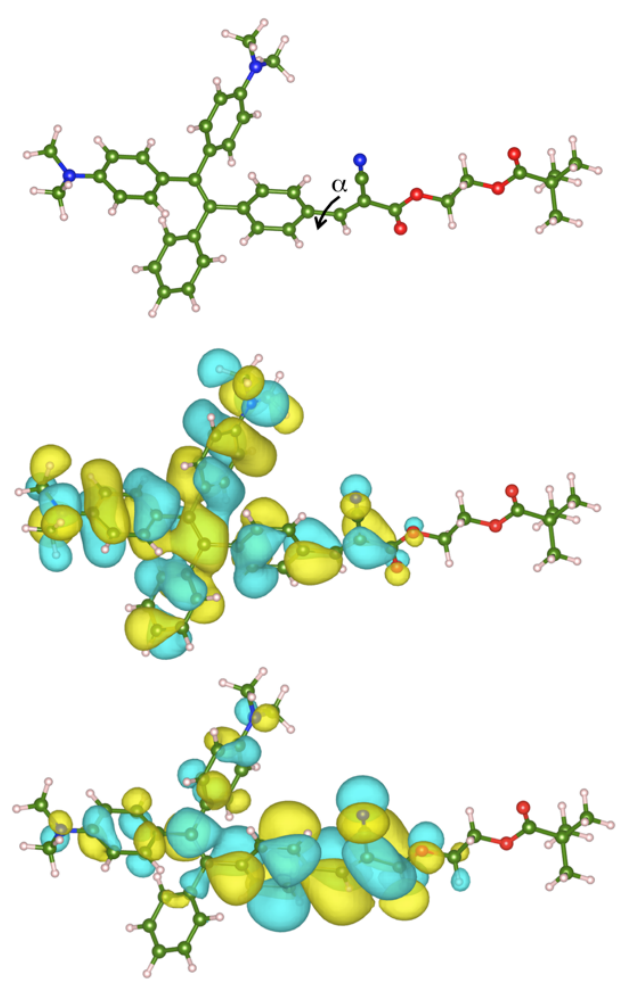

Figure 2. Top panel: Minimum-energy structure of DA_TPE (the $\mathrm{Br}$ atom has been substituted by a $\mathrm{CH}_{3}$ group), Central and bottom panels: iso-surface densities of DA_TPE HOMO and LUMO states that are involved in the electronic adsorption and emission processes. 


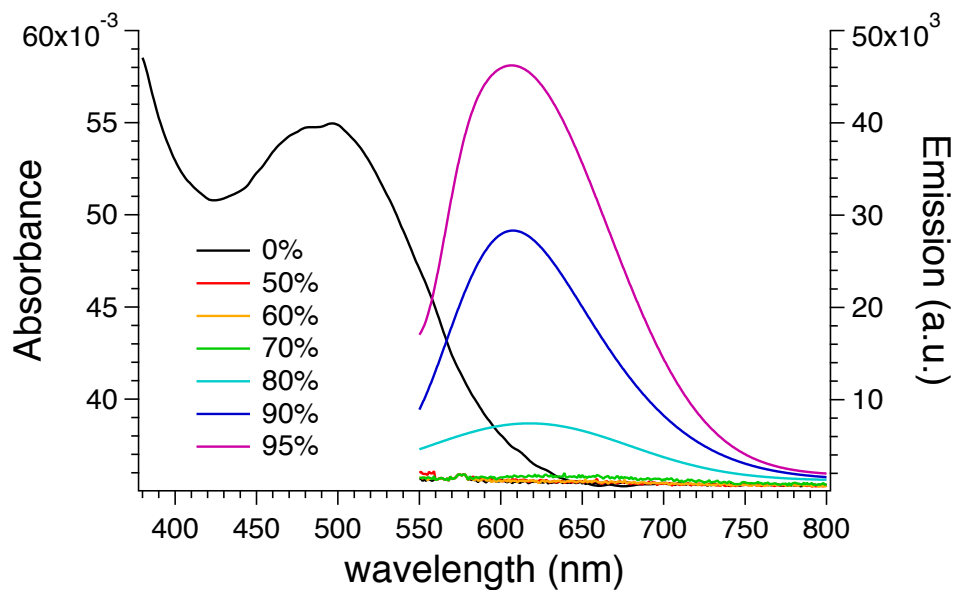

(a)

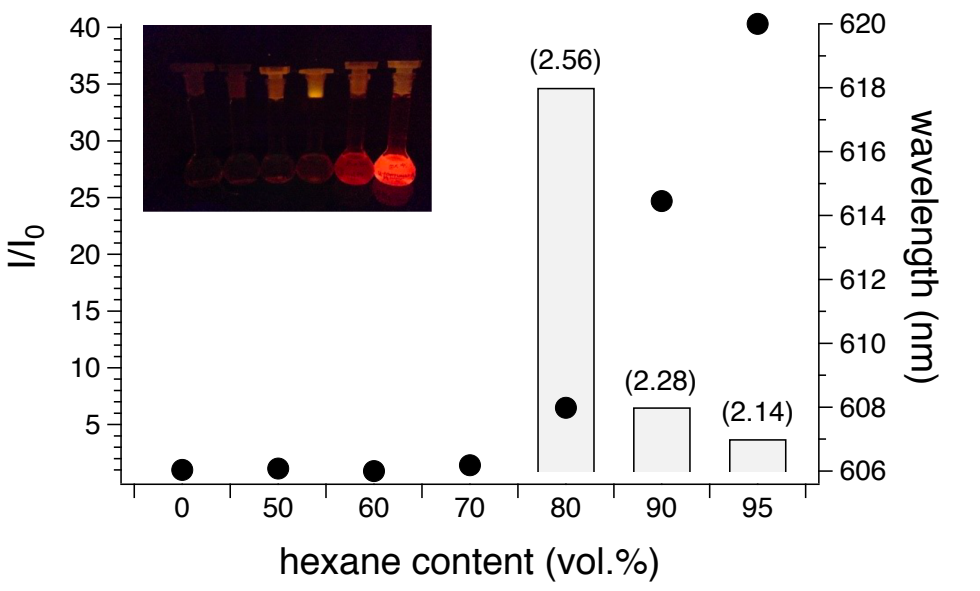

(b)

Figure 3. a) Absorption and emission $\left(\lambda_{\text {exc }}=490 \mathrm{~nm}\right.$ ) spectra of PMMA_TPE_RED 0.75 in $\mathrm{CHCl}_{3} /$ hexane mixtures with different hexane fractions (vol.\%); b) plot of relative emission intensity ( $1 / \mathrm{I}_{0}$, black circles) and emission maximum (grey bars) of PMMA_TPE_RED 0.75 versus the composition of the $\mathrm{CHCl}_{3}$ /hexane mixtures, where $\mathrm{I}_{0}$ is the emission intensity in $\mathrm{CHCl}_{3}$ solution. The values of the mixture dielectric constants are reported in the brackets. Inset: photographs of the same solutions taken under $365 \mathrm{~nm}$ UV light irradiation. PMMA_TPE_RED 0.75 concentration: $2 \mathrm{~g} / \mathrm{L}$. 


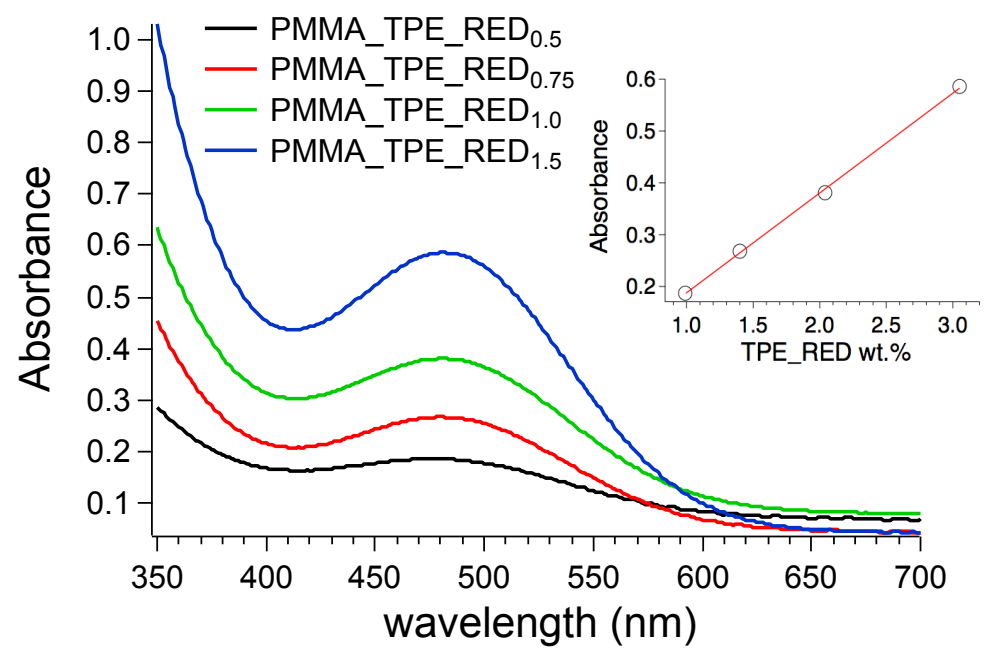

(a)

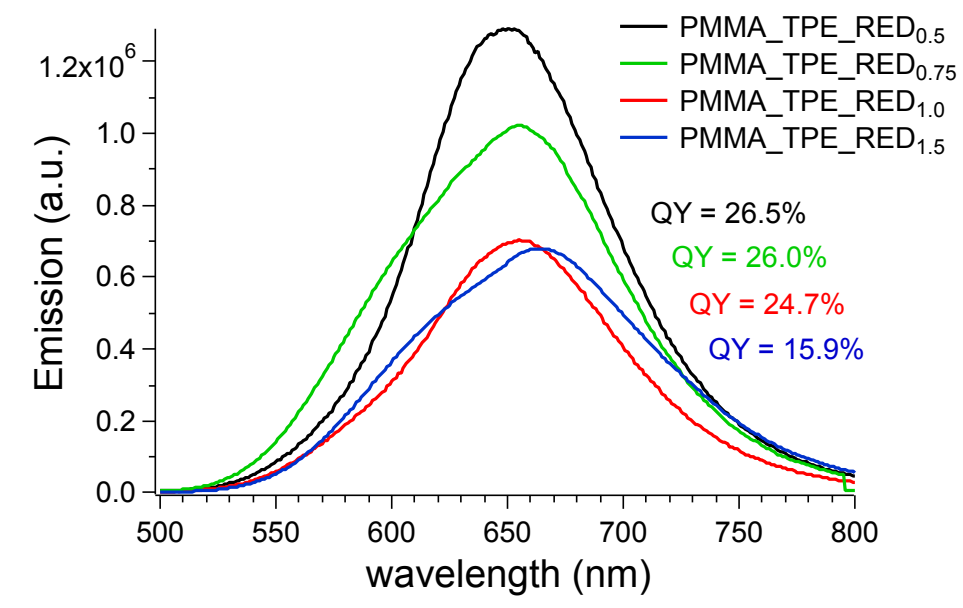

(b)

Figure 4. a) UV-vis absorption and b) emission spectra of PMMA_TPE_RED films as a function of fluorophore content. In the inset of figure $3 a$, the absorbance maximum was plotted as a function of the TPE_RED content in the polymer (see Table 1). In the inset of figure $3 b$, the QY values were reported for the corresponding film. Film thickness of $25 \pm 5 \mu \mathrm{m}$. 


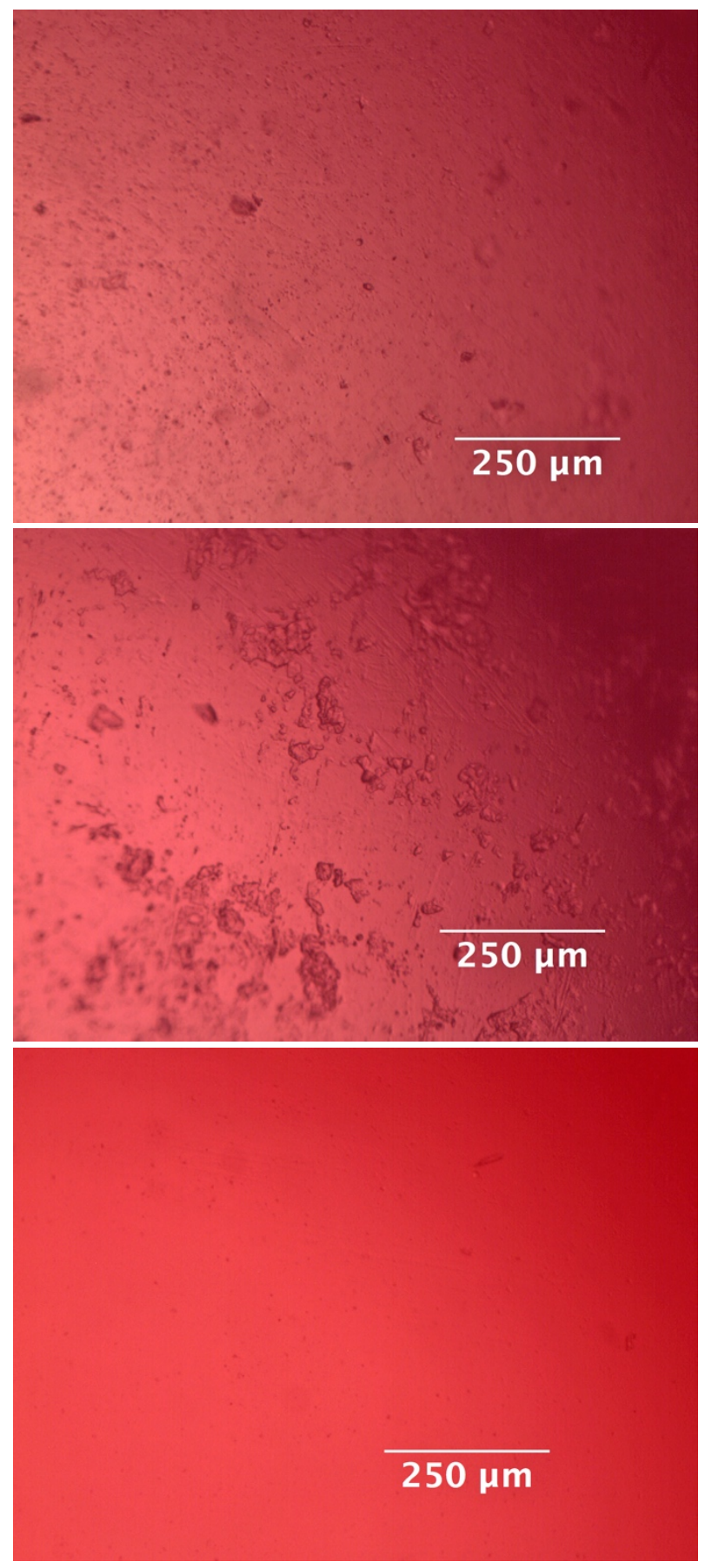

(a)

(b)

(c)

Figure 5. Optical microscopy images of a) PMMA_TPE_RED 0.50 , b) PMMA_TPE_RED 1.5 and a PMMA/ PMMA_TPE_RED 1.5 with a 1 wt.\% nominal content of TPE_RED 


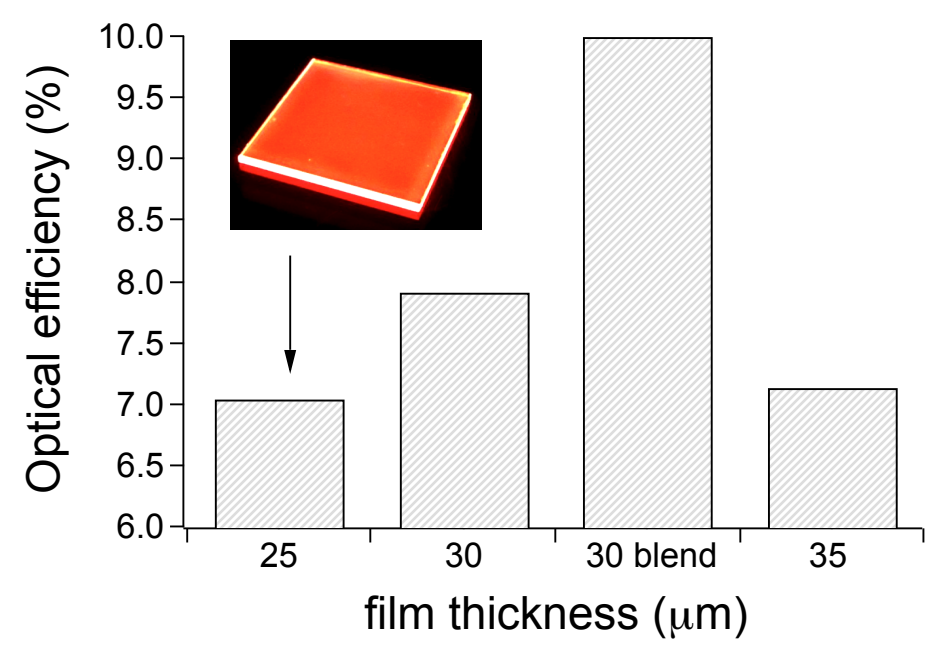

Figure 6. Optical efficiency of PMMA_TPE_RED 0.50 LSCS with different thickness and of a $30 \mu \mathrm{m}$ thick PMMA/PMMA_TPE_RED 1.5 with a 1 wt.\% nominal content of TPE_RED. Inset: $25 \mu \mathrm{m}$ thick of PMMA_TPE_RED 0.5 under the excitation with a Dark Reader 46B transilluminator ( $450 \mathrm{~nm}$ ) 


\section{Table of contents}

PMMA_TPE_RED polymers containing the 0.98-3.05 wt.\% of a red-emitting AIEgen were prepared and proposed as high performance luminescent solar concentrators

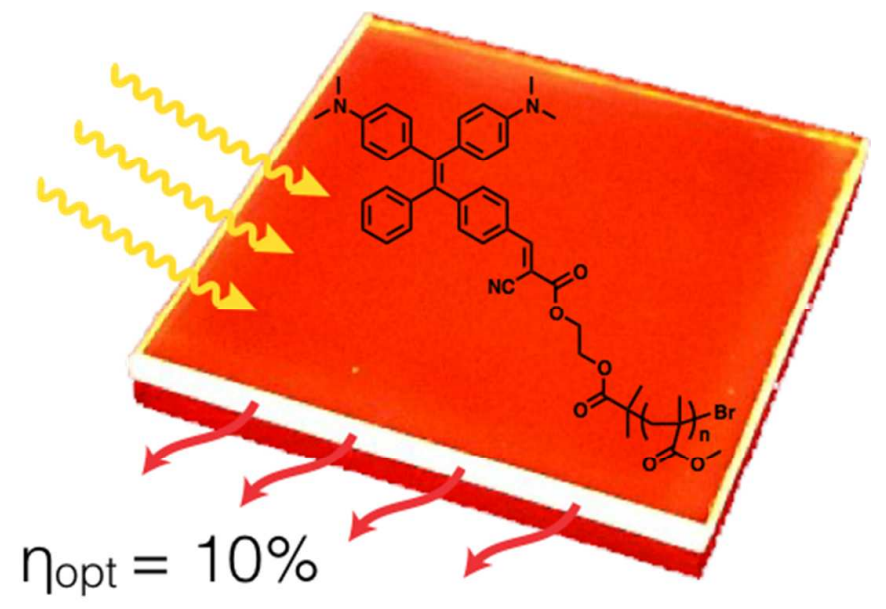




\section{Supplementary information for the manuscript}

"Luminescent solar concentrators based on PMMA films obtained from a redemissive ATRP initiator" by Riccardo Mori, Giuseppe lasilli, Marco Lessi, Ana Belén Muñoz-García, Michele Pavone, Fabio Bellina, and Andrea Pucci*

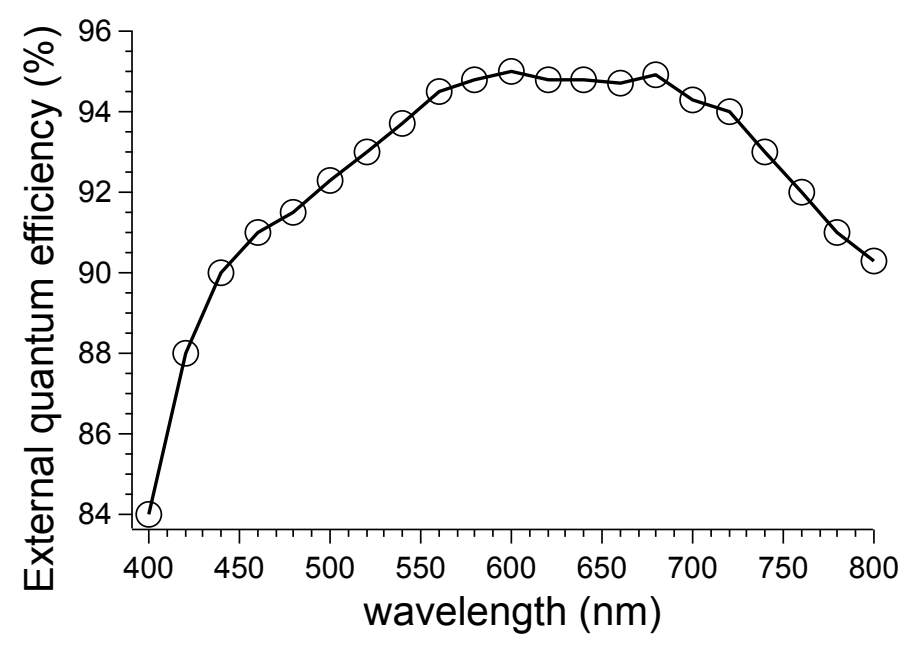

Figure S1. External quantum efficiency of the utilized Si-PV cell

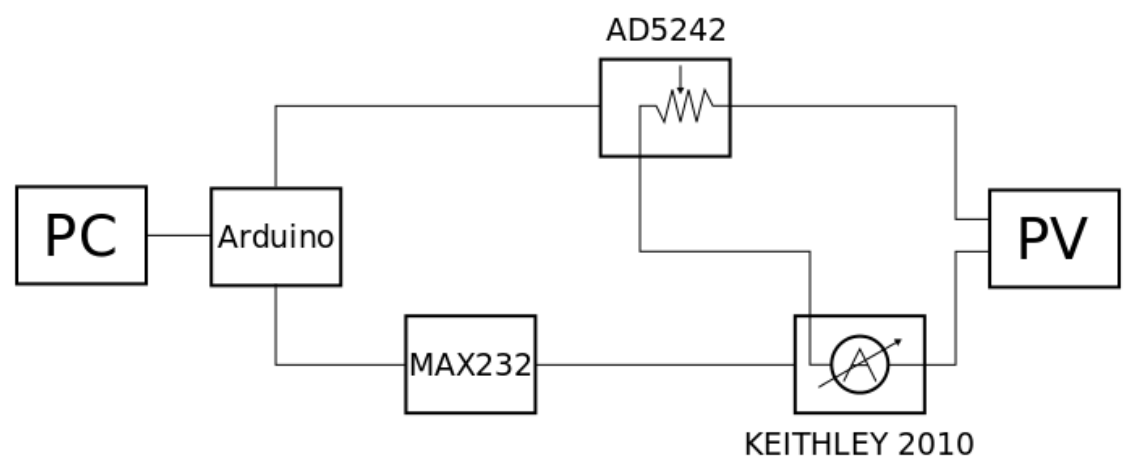

Figure S2. Scheme of the apparatus utilized for the photocurrent measurement

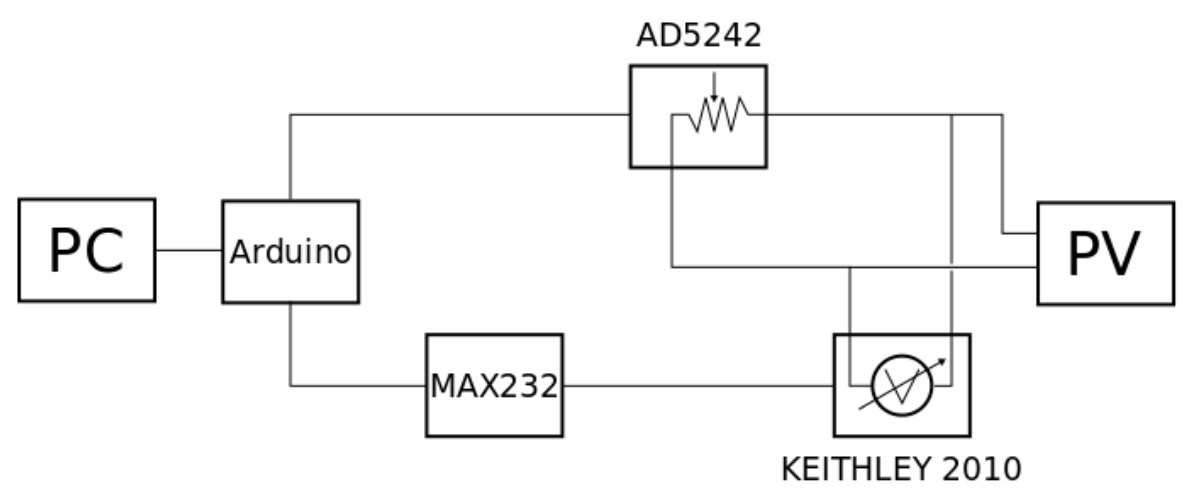


Figure S3. Scheme of the apparatus utilized for the voltage measurement

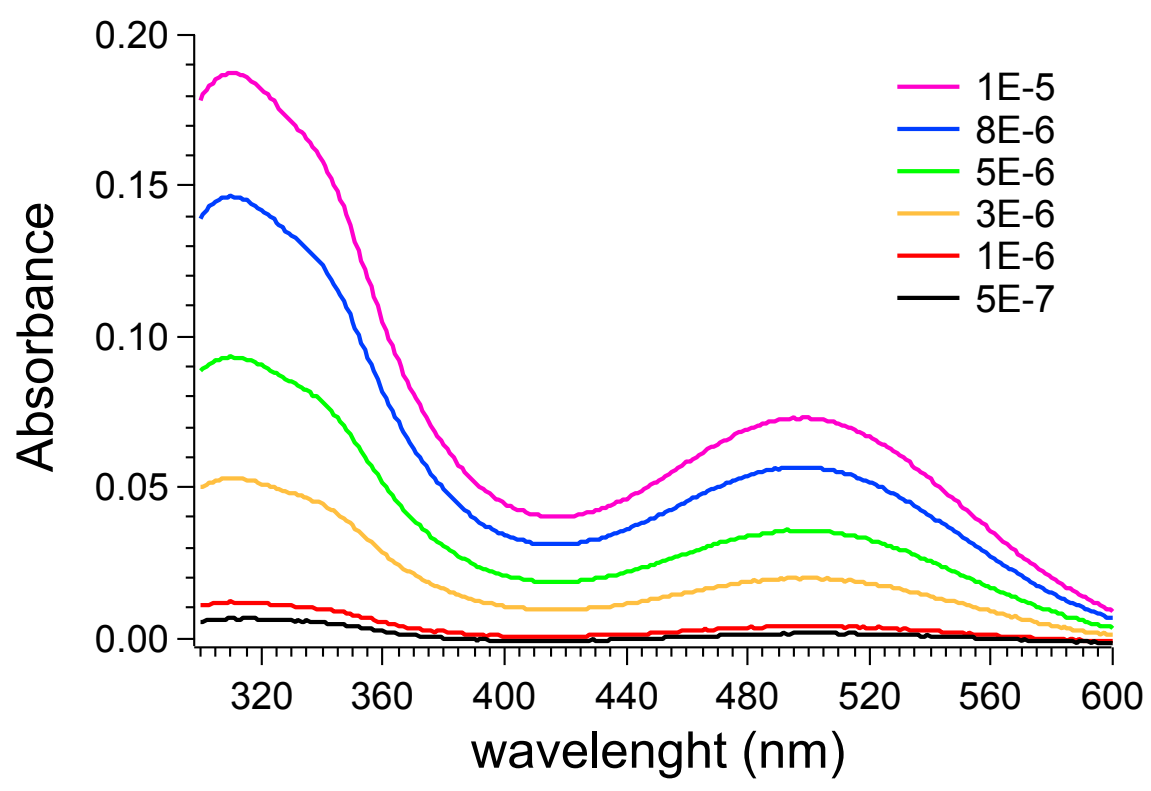

(a)

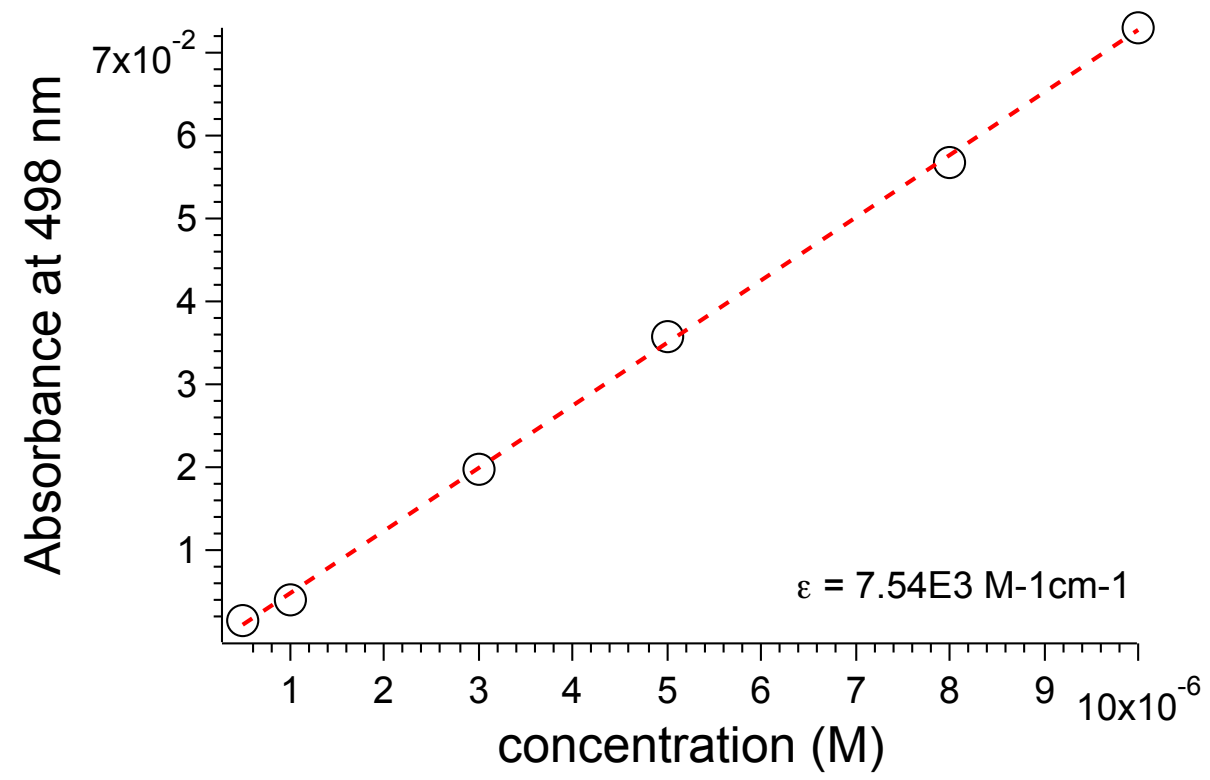

(b)

Figure S4. a) UV-vis absorption spectra of TPE_RED in DMSO solution as a function of fluorophore concentration (M) and $\mathrm{b}$ ) absorbance maximum plotted as a function of the TPE_RED content. 


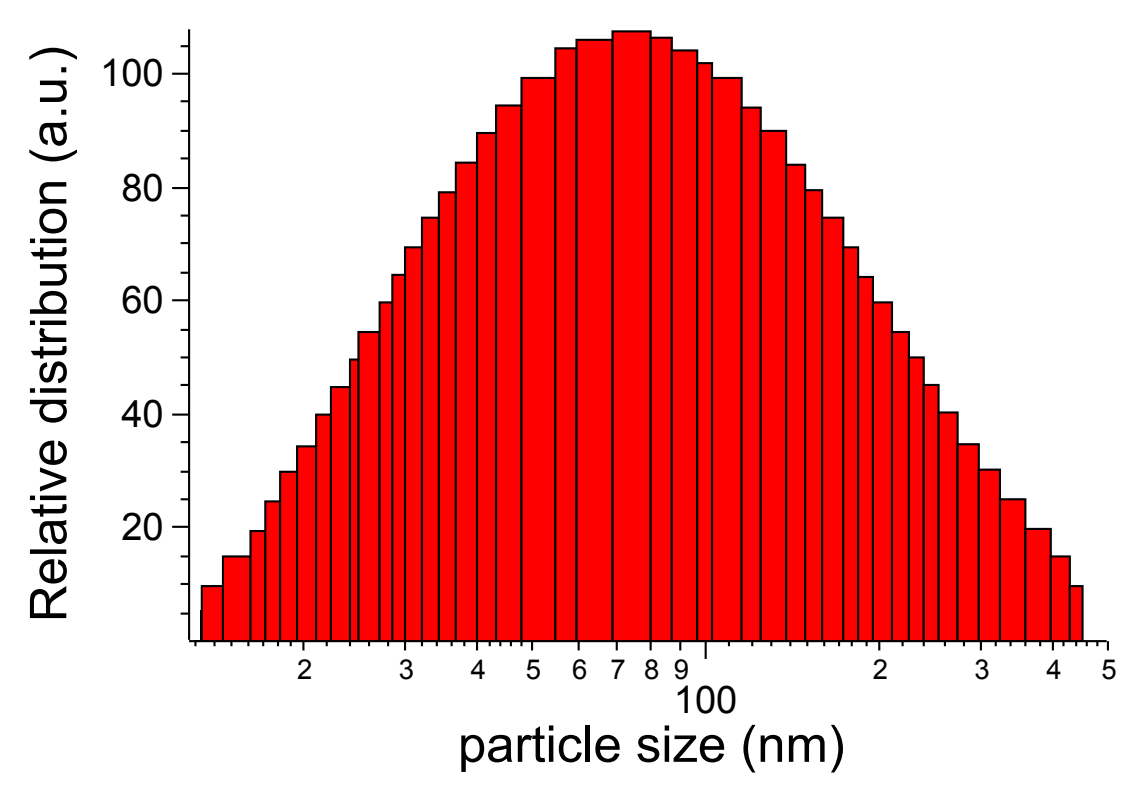

Figure S5. Size distribution of TPE_RED aggregates in DMSO/water mixtures with 95\% water fraction 


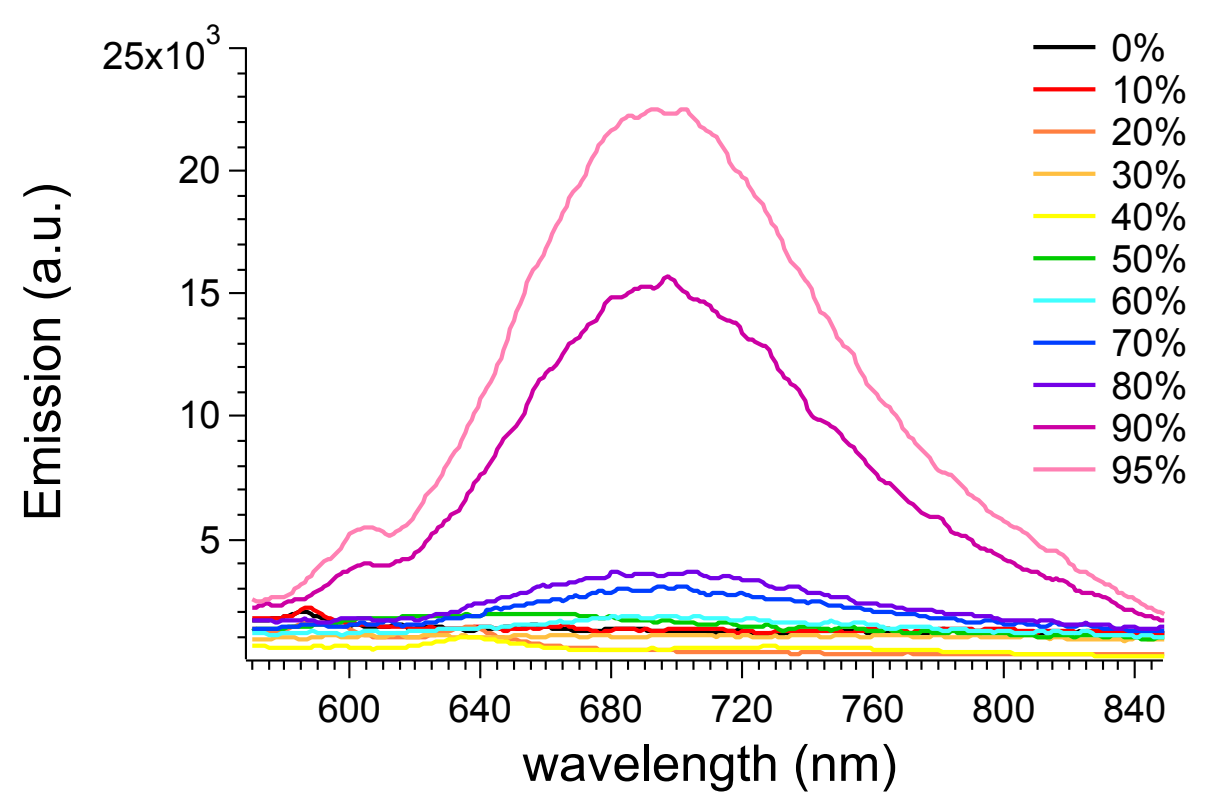

(a)

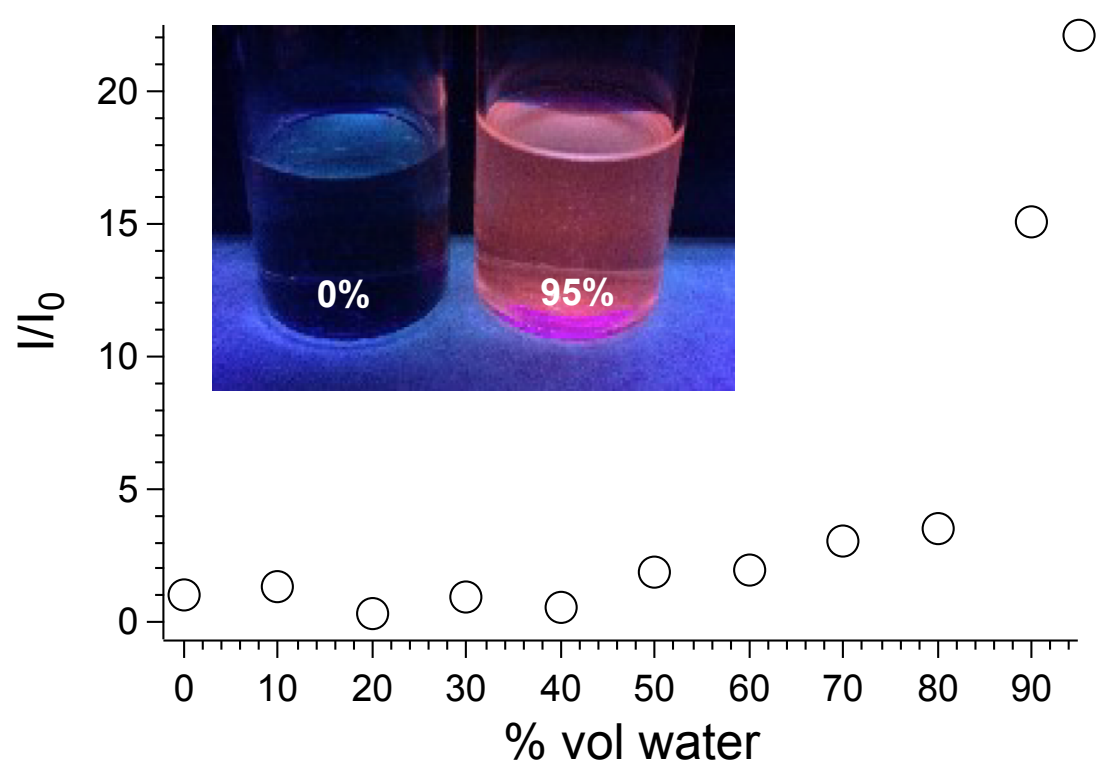

(b)

Figure S6. a) Fluorescence spectra of TPE_RED in DMSO/water mixture as a function of the water content (vol.\%) and b) emission intensity variations plotted as a function of the water content. In the inset, pictures of the same solutions taken under illumination with a near-UV lamp at $366 \mathrm{~nm}$ 


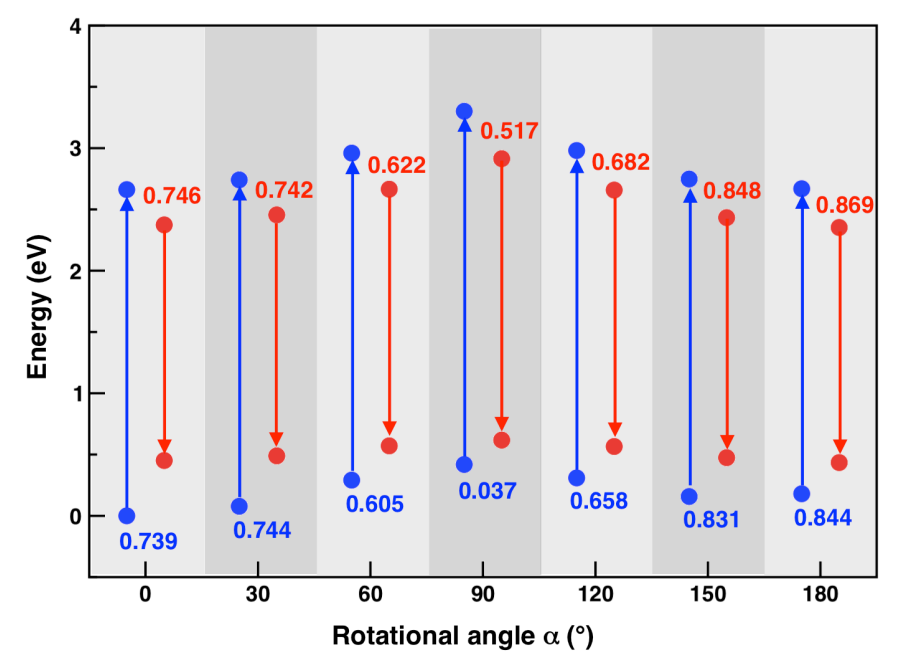

\begin{tabular}{|c|c|c|c|c|}
\hline$\alpha\left(^{\circ}\right)$ & $\Delta \mathrm{E}_{\mathrm{SO}}(\mathrm{eV})$ & $\Delta \mathrm{E}_{\mathrm{S} 1}(\mathrm{eV})$ & $\lambda_{\text {abs }}(\mathrm{nm})$ & Stokes Shift $(\mathrm{nm})$ \\
\hline 0 & 0 & 0 & 466 & 179 \\
\hline 30 & 0.078 & 0.115 & 453 & 178 \\
\hline 60 & 0.292 & 0.410 & 420 & 172 \\
\hline 90 & 0.419 & 0.584 & 377 & 163 \\
\hline 120 & 0.309 & 0.422 & 418 & 175 \\
\hline 150 & 0.158 & 0.180 & 452 & 181 \\
\hline 180 & 0.180 & 0.163 & 466 & 181 \\
\hline Opt. $^{\mathrm{a}}$ & - & - & 466 & 183 \\
\hline
\end{tabular}

a For optimized structures: $\alpha_{\mathrm{SO}}=2^{\circ}$ and $\alpha_{\mathrm{S} 1}=3^{\circ}$

Figure S7. Relative energies of the ground $\mathrm{S}_{0}\left(\Delta \mathrm{E}_{\mathrm{SO}}\right.$, blue dots) and excited $\mathrm{S}_{1}$ states $\left(\Delta \mathrm{E}_{\mathrm{S} 1}\right.$, red dots), plus absorption ( $\lambda_{\mathrm{abs}}$, blue arrows) and emission (red arrows) transitions of DA_TPE with respect to the rotation across the dihedral angle $\alpha$ (see Figure 2); the corresponding oscillator strengths $(f)$ are indicated in blue and red for absorption and emission transitions, respectively. Data computed at the CAM-B3LYP/TZVP/PCM level of theory on $S_{0}$ and $S_{1}$ optimized geometries by varying only the angle $\alpha$. 


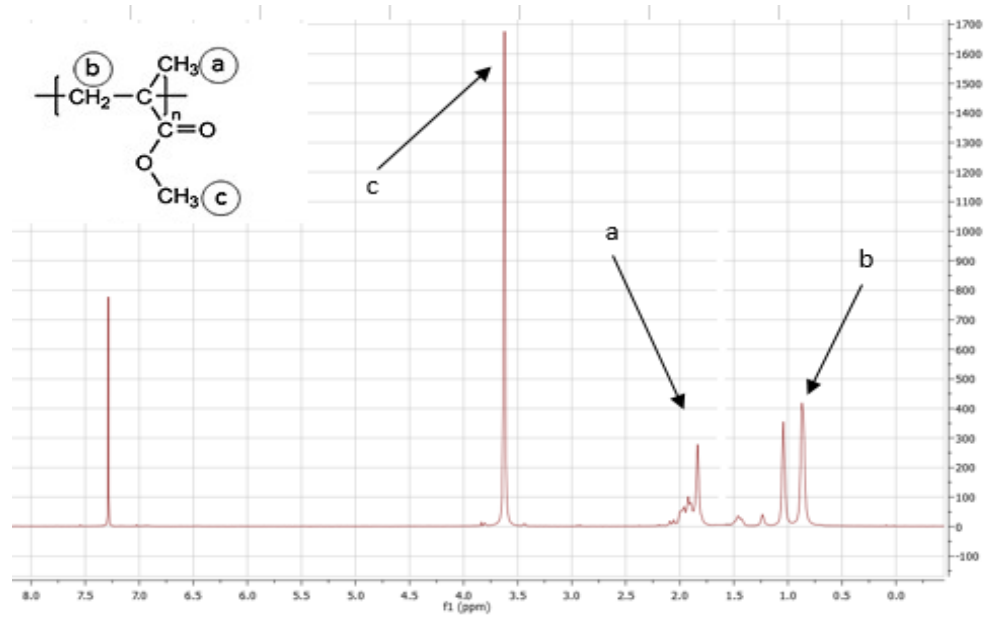

Figure S8. ${ }^{1} \mathrm{H}$ NMR of PMMA_TPE_RED 1.5

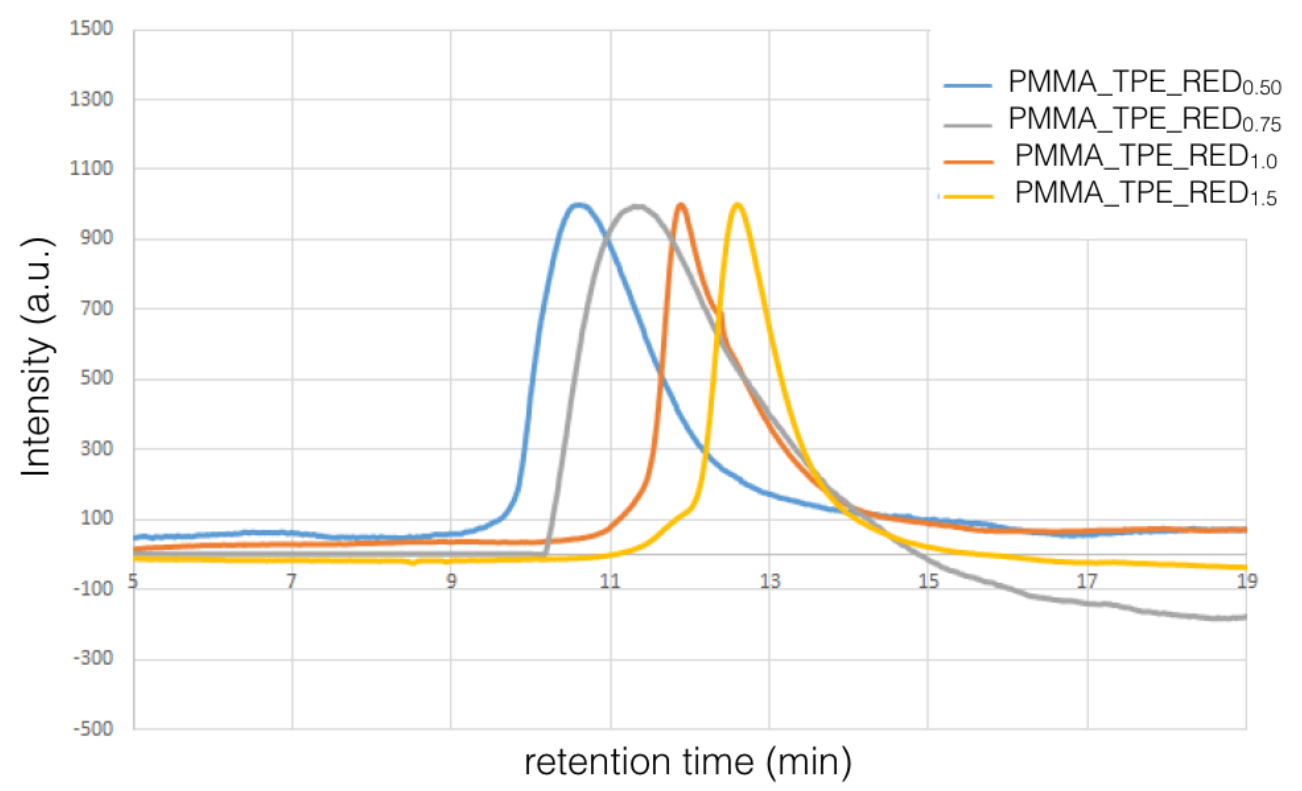

Figure S9. GPC analysis of the PMMA_TPE_RED polymers 


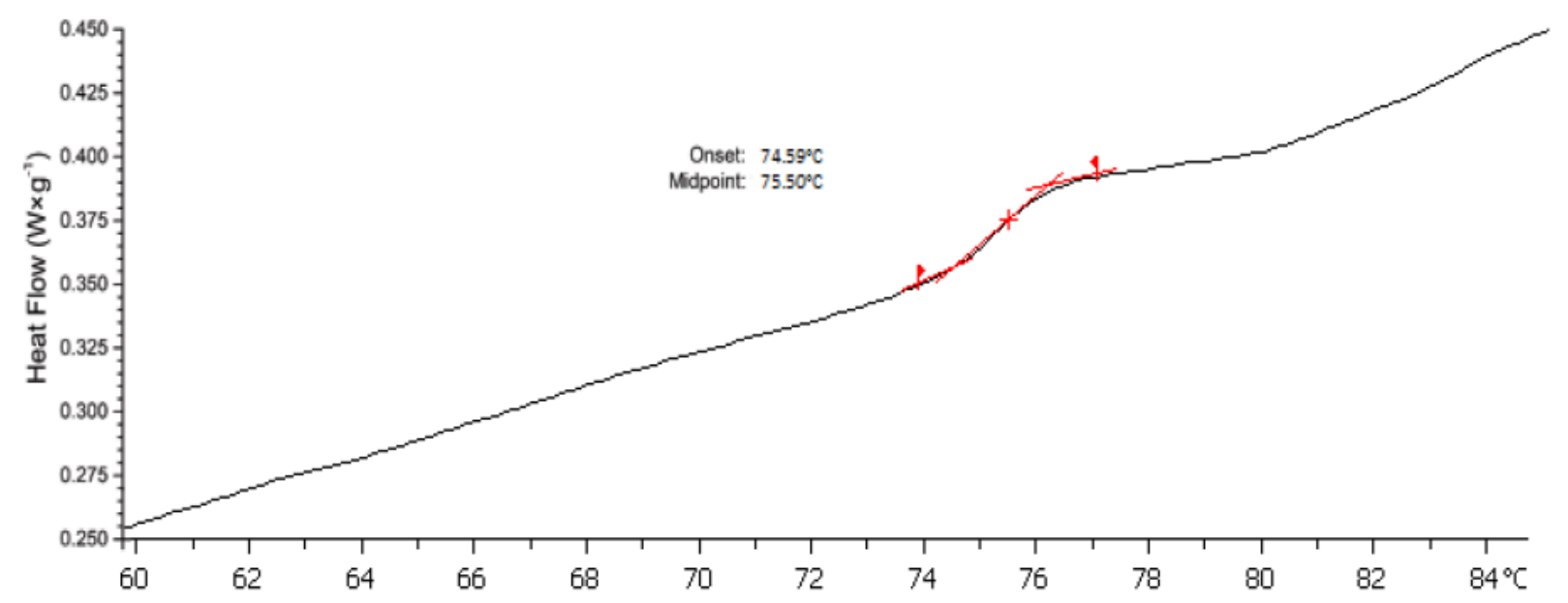

Figure S10. DSC analysis (second heating) of the PMMA_TPE_RED 0.75 